\title{
Stress-Induced Chronic Visceral Pain of Gastrointestinal Origin
}

\author{
Beverley Greenwood-Van Meerveld ${ }^{1,2,3 *}$ and Anthony C. Johnson ${ }^{3}$ \\ ${ }^{1}$ Oklahoma Center for Neuroscience, University of Oklahoma Health Science Center, Oklahoma City, OK, United States, \\ ${ }^{2}$ Department of Physiology, University of Oklahoma Health Science Center, Oklahoma City, OK, United States, ${ }^{3}$ VA Medical \\ Center, Oklahoma City, OK, United States
}

Visceral pain is generally poorly localized and characterized by hypersensitivity to a stimulus such as organ distension. In concert with chronic visceral pain, there is a high comorbidity with stress-related psychiatric disorders including anxiety and depression. The mechanisms linking visceral pain with these overlapping comorbidities remain to be elucidated. Evidence suggests that long term stress facilitates pain perception and sensitizes pain pathways, leading to a feed-forward cycle promoting chronic visceral pain disorders such as irritable bowel syndrome (IBS). Early life stress (ELS) is a risk-factor for the development of IBS, however the mechanisms responsible for the persistent effects of ELS on visceral perception in adulthood remain incompletely understood. In rodent models, stress in adult animals induced by restraint and water avoidance has been employed to investigate the mechanisms of stress-induce pain. ELS models such as maternal separation, limited nesting, or odor-shock conditioning, which attempt to model early childhood experiences such as neglect, poverty, or an abusive caregiver, can produce chronic, sexually dimorphic increases in visceral sensitivity in adulthood.

OPEN ACCESS

Edited by: Anna P. Malykhina, University of Colorado Denver School of Medicine, United States

Reviewed by: Jan D. Huizinga, McMaster University, Canada Patrick Anthony Hughes, University of Adelaide, Australia

*Correspondence: Beverley Greenwood-Van Meerveld beverley-greenwood@ouhsc.edu

Received: 29 September 2017 Accepted: 10 November 2017 Published: 22 November 2017

Citation:

Greenwood-Van Meerveld B and Johnson AC (2017) Stress-Induced

Chronic Visceral Pain of

Gastrointestinal Origin.

Front. Syst. Neurosci. 11:86. doi: 10.3389/fnsys.2017.00086
Chronic visceral pain is a classic example of gene $x$ environment interaction which results from maladaptive changes in neuronal circuitry leading to neuroplasticity and aberrant neuronal activity-induced signaling. One potential mechanism underlying the persistent effects of stress on visceral sensitivity could be epigenetic modulation of gene expression. While there are relatively few studies examining epigenetically mediated mechanisms involved in visceral nociception, stress-induced visceral pain has been linked to alterations in DNA methylation and histone acetylation patterns within the brain, leading to increased expression of pro-nociceptive neurotransmitters. This review will discuss the potential neuronal pathways and mechanisms responsible for stress-induced exacerbation of chronic visceral pain. Additionally, we will review the importance of specific experimental models of adult stress and ELS in enhancing our understanding of the basic molecular mechanisms of pain processing.

Keywords: stress, pain, colon, animal model, gastrointestinal tract, irritable bowel syndrome, brain, early life

\section{INTRODUCTION}

Chronic pain is defined as pain lasting longer than 3 months after the resolution or in the absence of an injury. Chronic visceral pain describes persistent pain emanating from the thoracic, pelvic, or abdominal organs that is poorly localized with regard to the specific organ affected. Here we will briefly review visceral pain pathways and their modulation by (i) stress in adulthood and (ii) 
following exposure to neonatal stress. We will provide an evidenced-based argument for the use of specific experimental models to advance the understanding of stress-induced chronic pain. We will explain the unique aspects of these models that allows for a carefully crafted investigation of the female vulnerability to stress-induced chronic visceral pain. Although the science of the epigenetics of human pain management is in its early stages with relatively few studies that have examined epigenetically mediated mechanisms involved in nociception in human subjects, a key aspect of the review will be to highlight the latest insights into epigenetic processes, including DNA methylation, histone modifications and microRNAs, and describe their involvement in the pathophysiology of chronic visceral pain.

\section{VISCERAL PAIN PATHWAYS}

Pain originating from the gastrointestinal (GI) system ascends to the brain via the same tri-neuronal pathways that convey noxious somatic stimuli. In the GI tract, nociceptive neurons, with cell bodies in the dorsal root ganglion (DRG), have free nerve endings that generally contain multiple receptor types that respond to various modalities, such as $\mathrm{pH}$, stretch, temperature, or the addition of specific chemicals such as chronic stress mediators (Million et al., 2006; Ochoa-Cortes et al., 2014; Vanner et al., 2016). Some of the receptors are cation channels, which can directly depolarize the nociceptor upon activation, while other receptors activate second messenger systems to change neuronal excitability by changing expression of, or modifying the function of, other cation channels. Nociceptors innervate all layers of the GI tract; nerve endings in the mucosa can be activated by luminal contents (digestive materials, bacteria, or bacterial metabolic products), or by signaling from enterochromaffin cells; nerve endings in the submucosal or the myenteric plexus are typically activated by local release of neurotransmitters and neuromodulators from intrinsic nerves or by resident immune cells; nerve endings within the muscle layers or blood vessels are typically activated by noxious stretch (Brookes et al., 2013; Barbara et al., 2016; Vanner et al., 2016). A small proportion of nociceptive neurons have dichotomous afferents that innervate both GI and adjacent organs, such as the bladder or overlying skin dermatomes (Schwartz and Gebhart, 2014). Once initiated within the periphery, the noxious signal is transmitted to the dorsal horn of the spinal cord where the first synapse

\footnotetext{
Abbreviations: IBS, irritable bowel syndrome; ELS, early life stress; GI, gastrointestinal; DRG, dorsal root ganglia; AMPA, $\alpha$-amino-3-hydroxy-5-methyl4-isoxazolepropionic acid; NMDA, N-methyl-D-aspartate; HPA, hypothalamicpituitary-adrenal; CORT, corticosterone or cortisol; CRH, corticotropin-releasing hormone; MR, mineralocorticoid receptor; GR, glucocorticoid receptor; CeA, central nucleus of the amygdala; WAS, water avoidance stress; $\mathrm{CB}_{1}$, cannabinoid receptor type 1; TRPV1, transient receptor potential cation channel subfamily $\mathrm{V}$ member $1 ; \mathrm{CRH}_{1}, \mathrm{CRH}$ type 1 receptor; $\mathrm{CRH}_{2}, \mathrm{CRH}$ type 2 receptor; 2AG, 2-arachidonoylglycerol; $\mathrm{CB}_{2}$, cannabinoid receptor type 2; FAAH, fatty acid amide hydrolase; MAGL, monoacylglycerol lipase; siRNA, small interfering RNA; GABA, gamma-amino butyric acid; $\mathrm{GABA}_{A}$, GABA type A receptor; $\mathrm{GABA}_{\mathrm{B}}$, GABA type $B$ receptor; mGlu, metabotropic glutamate receptor; HeCS, heterotypic chronic stress; BDNF, brain-derived neurotrophic factor; MS, maternal separation; miRNA, microRNA; ac-H3K9, acetylation of histone-3 at lysine- 9 .
}

occurs. Typically, the peripheral nociceptive neuron synapses on a cell body of a projection neuron within the superficial lamina of the dorsal horn of the spinal cord, the substantia gelatinosa or the nucleus proprius; however, unlike noxious signals arising from somatic structures synapsing at a specific spinal level, visceral afferents may synapse at multiple spinal levels, leading to diffuse localization of the noxious signal (Schwartz and Gebhart, 2014). Within the dorsal horn, the ascending pain signal can be modulated by local inhibitory interneurons and by descending projections from the brain stem (the periaqueductal gray, Raphe, or medulla) (Heinricher et al., 2009; Kuner, 2010; Denk et al., 2014). The projection neuron then sends a process to the contralateral side of the spinal cord to ascend to the brain in the anteriolateral columns, although some visceral afferent signals can also ascend in the ipsilateral dorsal columns (Palecek, 2004). The ascending fibers of the second order neurons are organized into the spinothalamic, the spinoparabrachial, and the spinoreticular tracts, depending on where the cell body of the third-order neuron is located (Almeida et al., 2004). The final primary synapse occurs at cell bodies within the brain. For the spinothalamic tract, the 3rd order neuron is within the thalamus, which acts as the primary hub for the central pain matrix (Morton et al., 2016). The thalamus is somatotopically organized such that noxious signals from the spinal cord are sent to specific regions of the primary somatosensory cortex for the localization of the signal. In contrast, the cortical localization for visceral pain is typically less precise since the ascending signal often innervates the spinal cord at multiple levels and pain signals from visceral and somatic sources may be transmitted by the same 2 nd order spinal neuron (viscerosomatic convergence). Within the central pain matrix, the thalamus signals to brain regions that process the emotional component of the pain signal, such as the amygdala, insula, anterior cingulate cortex, hippocampus, and nucleus accumbens (Wilder-Smith, 2011; Bushnell et al., 2013). In healthy individuals, activation of the central pain matrix provides the appropriate behavioral responses (unpleasant emotion, guarding, and/or immobilization of the affected site) to promote recovery and to learn avoidance to prevent future injury (Navratilova and Porreca, 2014). Descending antinociceptive brainstem pathways are also activated by the central pain matrix to decrease noxious signaling at the dorsal horn of the spinal cord by changing the excitability of the 2nd order neuron within the spinal cord (Heinricher et al., 2009; Denk et al., 2014).

\section{MECHANISMS RESPONSIBLE FOR CHRONIC VISCERAL PAIN}

Sensitization of the primary (peripheral afferent), secondary (spinal), or tertiary (brainstem/thalamic) neuron can promote chronic pain signaling (Fornasari, 2012). For visceral pain, peripheral sensitization can occur in response to tissue injury or due to release of inflammatory mediators (chemokines, corticotropin-releasing hormone, cytokines, histamine, proteases, prostaglandins, serotonin) in response to injury or infection (Arroyo-Novoa et al., 2009; Widgerow and Kalaria, 
2012). Furthermore, in response to the peripheral stimuli, the afferent fibers can release neuromodulators (calcitonin gene related peptide, nitric oxide, substance $\mathrm{P}$ ) that act as paracrine agents to further stimulate nerve activity. Prolonged exposure to these mediators leads to activation of second messenger signaling cascades that can alter phosphorylation and/or expression receptors (particularly cation channels), promoting persistent changes in the electrical properties of the neuron such as lowering action potential threshold or increasing the number of action potentials upon reaching threshold (Woolf and Salter, 2000). Since neuronal sensitization is induced by activation of G-protein coupled receptors that respond to algesic chemicals, and they signal through common second messenger systems, pharmaceuticals targeting these systems could represent a novel approach to treat chronic pain conditions (Reichling and Levine, 2009). Alternatively, the cellular excitability is maintained by ion channels with kinetic properties or expression patterns altered by the second messenger phosphorylation systems, which also represents valid targets for new therapies for chronic pain (Schaible et al., 2011; Stemkowski and Smith, 2012).

Following sensitization of primary nociceptive afferents, the enhanced neuronal excitability increases neurotransmitter and neuromodulator release within the dorsal horn of the spinal cord. Typically the nociceptors use glutamatergic signaling, to activate ionotropic $\alpha$-amino-3-hydroxy-5-methyl-4-isoxazolepropionic acid (AMPA) and N-methyl-D-aspartate (NMDA) receptors on the target neuron, with co-release of neuromodulators, such as substance $\mathrm{P}$, to activate similar second-messenger systems to modulate the function of the second order neuron (Woolf and Salter, 2000). The primary function of the second messenger signaling to is to change the expression of AMPA and NMDA receptors, in particular by recruiting a calcium permeable AMPA receptor variant to the plasma membrane to increase the overall excitability of the neuron (Tao, 2012). Thus, even if the peripheral nociceptive afferent is able to reverse the sensitization once the acute injury has healed, the second order neuron will still be able to reach action potential thresholds with less neurotransmitter release from the primary afferent due to the increased calcium permeability. A second, concurrent mechanism to promote dorsal horn sensitization occurs due to disinhibition of inhibitory interneurons, either due directly from signaling from the primary afferent affecting receptors on the inhibitory interneuron, or indirectly by decreasing the endogenous descending noxious inhibition from the brainstem (Zeilhofer et al., 2012; Braz et al., 2014). Overall, increased peripheral excitability with decreased inhibitory tone leads to remodeling and persistent excitation of the second order neuron, which promotes chronic pain.

Finally, sensitization of the central pain matrix can directly promote and maintain chronic pain. The central pain matrix is composed of the limbic and cortical brain areas that respond to the emotional and physical components of pain. Increased afferent nociceptive neurotransmission due to peripheral or spinal sensitization can invoke similar central remodeling to cause persist pain (Jaggi and Singh, 2011). Initially, the 3rd order neurons within the thalamus or brainstem receive the enhanced activity from the spinal cord, causing additional signaling to the other cortical and limbic regions of the pain matrix. The integration nuclei, such as the amygdala, hippocampus, insula, or cingulate, are subsequently sensitized in response to the increased afferent stimulation, which can change activation thresholds, change previously innocuous stimuli to be perceived as noxious, and cause the negative emotional responses to chronic pain (Staud, 2012). An additional consequence of the central remodeling of the pain matrix is the loss of descending inhibition of the ascending noxious signals, which has been demonstrated in brain imaging studies of patients with chronic pain conditions, including visceral pain disorders (Ossipov et al., 2000; Heinricher et al., 2009; Wilder-Smith, 2011; Saab, 2012).

\section{STRESS MODULATION OF CENTRAL PATHWAYS IN CHRONIC VISCERAL PAIN}

While the previous description was presented as a "bottom-up" model of sensitization leading to chronic visceral pain, direct sensitization of the central pain matrix can drive a "top-down" mechanism wherein stress and negative emotions can promote enhanced perception of nociception in the absence of overt peripheral injury (Scarinci et al., 1994; Lampe et al., 2003; Maizels et al., 2012; Racine et al., 2012). The body's response to stress is composed of two parallel systems: the quick "flight or fight" of the sympathomedullary axis and the slower hypothalamic-pituitaryadrenal (HPA) axis. The sympathetic response to acute stress mobilizes epinephrine and norepinephrine to change bloodflow away from the skin and GI tract toward the muscles along with providing a burst of energy and a dampening of pain perception to allow the individual to run or fight for survival. The neuroendocrine response mediated by the HPA axis causes release of cortisol in humans or corticosterone in rodents (CORT) to mobilize glucose reserves to restore homeostasis after an acute stressor, or to cause long-term changes in metabolic function and neuronal sensitivity following chronic stressors. Typically, the sympathetic response will habituate to repeated stressors, whereas the HPA response may or may not habituate depending on the type, duration, and variability of the stressor. As implied by the name, the HPA axis is initiated when paraventricular nucleus of the hypothalamus secretes the 41amino acid peptide corticotropin-releasing hormone (CRH) into the hypophyseal portal circulation in response to a stressor. After binding to corticotrophs in the anterior pituitary, CRH causes the release of the 39-amino acid peptide adrenocorticotropic hormone into the systemic circulation after being cleaved from its 241-amino acid precursor protein, proopiomelanocortin. After binding in the adrenal cortex, adrenocorticotropic hormone induces de novo synthesis of CORT from a cholesterol-derived steroid precursor, which then enters systemic circulation bound to a carrier protein (cortisol binding globulin). In addition to its metabolic functions, CORT binding to its high affinity mineralocorticoid receptor (MR) and low affinity glucocorticoid receptor (GR) within brain regions such as the hippocampus, the paraventricular nucleus of the hypothalamus, and some cortical regions induces negative feedback to terminate the response of 
the HPA axis, while binding at the amygdala opposes the feedback inhibition by increasing CRH expression and facilitation of the stress axis (Sapolsky et al., 1983; Reul and de Kloet, 1985; Herman and Cullinan, 1997; Schulkin et al., 1998; Shepard et al., 2000). In particular, the central nucleus of the amygdala (CeA) integrates viscerosensory signaling with neuroendocrine and autonomic responses to stressors, and is primed to influence both stress and pain signaling though expression of MR, GR, and CRH (Myers and Greenwood-Van Meerveld, 2010a, 2012; Johnson and Greenwood-Van Meerveld, 2015; Johnson et al., 2015). Additionally, following chronic stress exposure, evidence points to neuronal remodeling that is region specific. For example, in a stress-inhibitory region, such as the hippocampus, dendritic structure is simplified (less synaptic connections, weakened circuit) whereas in the stress-facilitatory amygdala dendrites becomes more complex in structure (more synaptic connections, strengthened circuit) (Woolley et al., 1990; Vyas et al., 2002; Mitra and Sapolsky, 2008; Radley et al., 2013). The likely net effect of this neuronal remodeling following chronic stressors is the exacerbation of pain perception and the promotion of chronic pain symptomatology due to the loss of anti-nociceptive and anti-stress signaling within the central pain matrix combined with facilitation of nociceptive and stress-responsive signaling. These remodeled pain circuits also impinge on the function of key brainstem regions that modulate descending pain inhibition. The periaqueductal gray and rostral ventral medulla form an integrative circuit that modules ascending pain signals with function influenced by inhibitory connections from cortical brain regions and facilitatory connections from the amygdala (da Costa Gomez and Behbehani, 1995; Price, 1999). A direct integration of the sympathomedullary and HPA axis is achieved by CRHergic connections from the amygdala to the locus coeruleus and norepinephrine-ergic connections from the locus coeruleus to the amygdala (Reyes et al., 2011). Clinically, the effect of chronic stress on visceral pain is best illustrated by the high comorbidity of anxiety, depression, and other psychiatric disorders with functional pain disorders, such as irritable bowel syndrome (IBS) (Drossman et al., 2011; Hooten, 2016). Because there are multifactorial mechanisms that can induce chronic visceral pain, further research is necessary to identify specific mechanisms underlying the development of chronic stress-induced visceral pain.

\section{NEUROTRANSMITTERS IN STRESS PATHWAYS THAT MODULATE VISCERAL NOCICEPTION}

Multiple studies using preclinical models of experimentally induced stress have identified a plethora of neurotransmitters and neuromodulators capable of promoting stress-induced visceral hypersensitivity. An exhaustive description of every target is beyond the scope of the current review, but many recent publications have highlighted some of the various modulators (Mora et al., 2012; Asan et al., 2013; Reichling et al., 2013; Timmermans et al., 2013; Grace et al., 2014; Greenwood-Van Meerveld et al., 2015). Here we aim to focus on specific targets within both the stress and pain circuits that play a key role in the development of visceral hypersensitivity in chronic visceral pain models (Figure 1).

\section{Role of Corticosteroids in Stress-Induced Visceral Hypersensitivity}

GR and MR are in the 3-ketosteroid nuclear receptor superfamily that also includes androgen and progesterone receptors (Lu et al.,

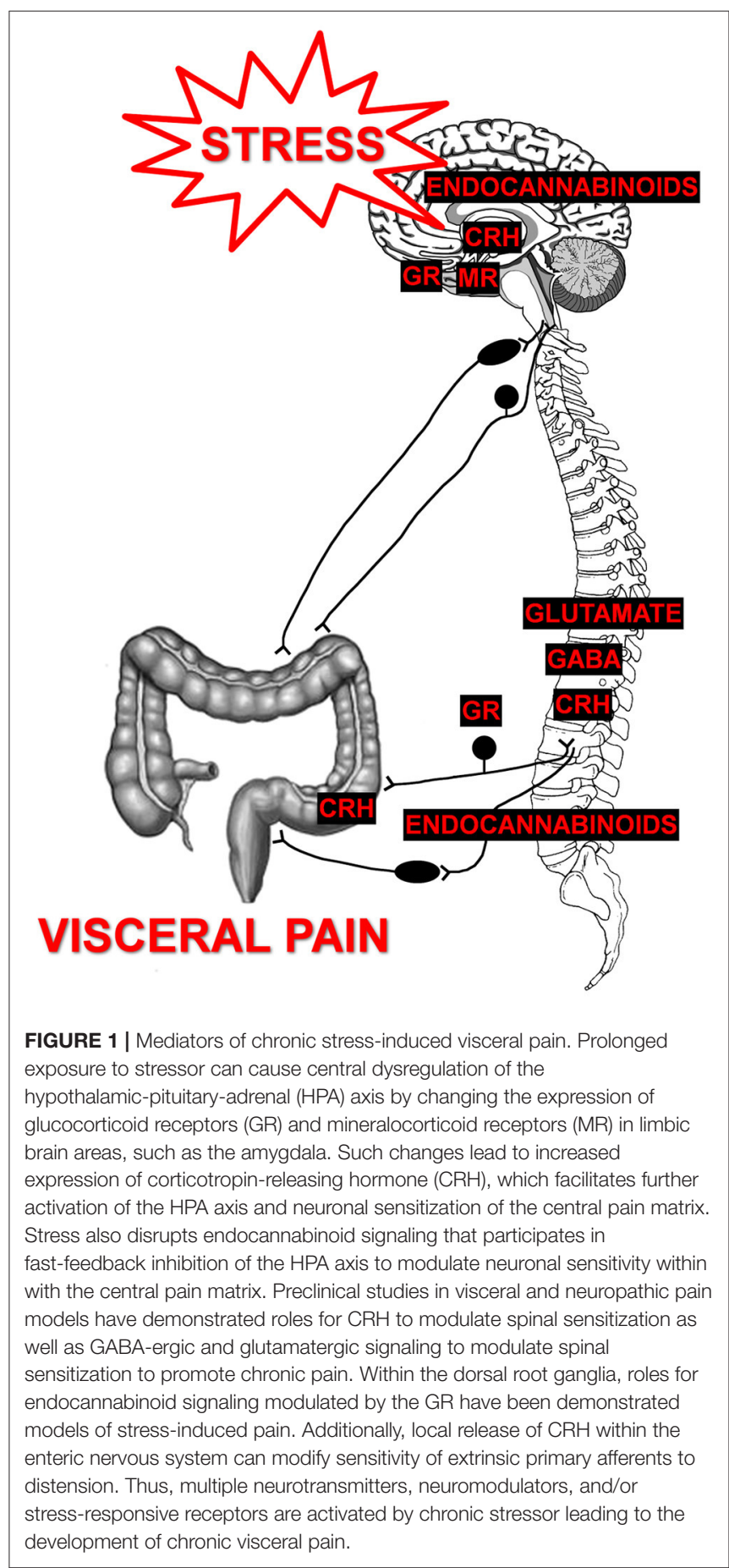


2006; Alexander et al., 2015a). Originally, GR and MR were characterized as cytoplasmic transcription factors responsible for changing cellular processes over hours, days, or weeks due to changes in expression of target genes (de Kloet et al., 2005). More recently, there is compelling evidence for membrane bound versions of both GR and MR leading to changes in function within minutes of binding, including participating in regulation of feedback inhibition of the HPA axis (Di et al., 2003; Haller et al., 2008; Evanson et al., 2010; Prager et al., 2010; Hammes and Levin, 2011). Within the brain, MR expression is restricted to key nuclei such as the hippocampus and amygdala. In contrast, GR is expressed throughout the brain, and both the cytoplasmic and membrane versions are typically present to balance the fast and slow effects of either receptor to produce the correct response to an acute stressor (Johnson et al., 2005; Karst et al., 2005; Lu et al., 2006; Evanson et al., 2010; Prager et al., 2010). Following neuronal remodeling by chronic stress, the balance between the effects of the receptors is disrupted, promoting chronic stressinduced pain due to altered signaling within the central pain matrix (Johnson and Greenwood Van-Meerveld, 2012). There are many studies demonstrating that manipulating GR or MR signaling with selective antagonists or via knockdown of receptor expression can modulate neuropathic pain circuits, particularly those with a spinal site of action (Wang et al., 2004; Takasaki et al., 2005; Gu et al., 2007; Dina et al., 2008; Dong et al., 2012).

Multiple studies suggest that stress-induced changes in GR and/or MR expression within the nervous system (DRG, spinal cord, or brain) can directly affect colonic sensitivity, suggesting that dysregulation of these receptors participates chronic visceral pain. In support, we have shown that exposing $\mathrm{GR}$ and $\mathrm{MR}$ receptors in the CeA, via stereotaxic application, either to the non-selective agonist CORT, to the selective GR agonist dexamethasone, or to the selective MR agonist aldosterone, induces colonic hypersensitivity with inhibition of the effects through co-application of selective antagonists (Myers and Greenwood-Van Meerveld, 2007, 2010a; Myers et al., 2007). Using the stereotaxic implantation model, we found that persistent visceral hypersensitivity was associated with a long-term decrease in GR expression within the CeA (Tran and Greenwood-Van Meerveld, 2012). Building upon these observations, we were the first to demonstrate that a central epigenetic mechanism within the CeA involving changes in histone acetylation was responsible for the longterm decrease in amygdala GR expression and persistent colonic hypersensitivity (Tran et al., 2015). In a similar fashion, repeated exposure of a rat to water avoidance stress (WAS) induced changes in methylation of the GR promoter within the CeA leading to decreased GR expression and colonic hypersensitivity through a mechanism involving an increase in CRH (Tran et al., 2013). The WAS-induced colonic hypersensitivity could also be inhibited by stereotaxic application of selective GR or MR antagonist to the CeA (Myers and Greenwood-Van Meerveld, 2012), or following systemic administration of a GR antagonist (Hong et al., 2011). The role of GR and MR receptors in the $\mathrm{CeA}$ for the modulation of colonic sensitivity was demonstrated by mimicking the stress-induced decrease in expression of the receptors through the use of selective antisense oligodeoxynucleotides to knockdown expression of either receptor in the $\mathrm{CeA}$, which was sufficient to induce colonic hyperalgesia in stress-naïve rats (Johnson and Greenwood-Van Meerveld, 2015). Further evidence was reported in female rats exposed to early-life stress (ELS) with colonic hypersensitivity in adulthood that displayed an increase, rather than a decrease, in GR expression within the CeA; however, the ELS-induced colonic hypersensitivity was exacerbated following GR mRNA antisense oligodeoxynucleotides administration into the CeA, suggesting additional neurotransmitter systems underlying ELSinduced colonic hypersensitivity (Prusator and Greenwood-Van Meerveld, 2017). In a two-hit model of colonic hypersensitivity induced by both neonatal and adult noxious colonic distension, reduced hippocampal GR expression was associated with colonic hypersensitivity (Zhang et al., 2016b). Further evidence for a central regulation of ELS-induced colonic hypersensitivity was reported in a model of maternal separation in which colonic hypersensitivity in adult male rats was inhibited via an acute microinjection of either a GR or MR antagonist into the right CeA (Zhou X. P. et al., 2016). There is also experimental evidence for a role for steroid receptors within the periphery in the development of stress-induced colonic hypersensitivity (Hong et al., 2011). In response to repetitive exposure to a water avoidance stressor, male rats exhibited a decrease in GR expression in L6-S2 DRG. Subsequent experiments from the same investigators found that the decrease in GR expression was due to increased methylation of the GR promoter pointing to an epigenetic mechanism at the level of the spinal cord in the induction of chronic visceral hypersensitivity (Hong et al., 2015).

\section{Role of Corticotropin-Releasing Hormone (CRH) in Stress-Induced Visceral Hypersensitivity}

$\mathrm{CRH}$ is released from the paraventricular nucleus of the hypothalamus to initiate the HPA axis in response to stress, and is also highly expressed within the CeA (Gallagher et al., 2008). $\mathrm{CRH}$ binds to its high-affinity $\mathrm{CRH}$ type 1 receptor $\left(\mathrm{CRH}_{1}\right)$ and its lower affinity $\mathrm{CRH}$ type 2 receptor $\left(\mathrm{CRH}_{2}\right)$, both of which are G-protein coupled receptors (Alexander et al., 2015b). While activation of both receptors increases intracellular cAMP, they produce opposing effects on behavior; $\mathrm{CRH}_{1}$ activates the stress response and enhances nociception, while $\mathrm{CRH}_{2}$ inhibits the stress response and decreases nociception in rodents (Ji and Neugebauer, 2007, 2008; Yarushkina et al., 2009; Tran et al., 2014). Clinical studies have found that CRH within the cerebrospinal fluid was positively correlated with pain perception in patients with chronic pain (McLean et al., 2006). A non-selective $\mathrm{CRH}$ antagonist decreased pain induced by colonic distension, while intravenous $\mathrm{CRH}$ induced esophageal hypersensitivity to distension in healthy volunteers, with no changes in perception of other noxious stimuli (Sagami et al., 2004; Broers et al., 2017). Intravenous CRH also increased abdominal pain and amygdala blood flow in both healthy volunteers and IBS patients (Tanaka et al., 2016). In adult rodent 
models of stress, there is evidence for modulation of colonic hypersensitivity by both central and peripheral $\mathrm{CRH}$ receptors. We have shown that $\mathrm{CRH}$ expression in the CeA acting via $\mathrm{CRH}_{1}$ receptors mediates colonic hypersensitivity in adult female rats following neonatal exposure to ELS as well as persistent colonic hypersensitivity induced by adulthood stress in male rats (Johnson et al., 2015; Prusator and Greenwood-Van Meerveld, 2017). Further supporting evidence for a role of amygdala $\mathrm{CRH}$ in stress-induced visceral sensitivity demonstrated that intra-CeA CRH administration increased colonic sensitivity via $\mathrm{CRH}_{1}$ receptor activation in stress-naïve male rats ( $\mathrm{Su}$ et al., 2015). Peripheral administration of a $\mathrm{CRH}_{1}$ antagonists dose-dependently reduced stress-induced colonic sensitivity and decreased stress-induced fecal pellet output (Million et al., 2013; Taguchi et al., 2017). Similarly, a peripherally restricted $\mathrm{CRH}_{1}$ agonist induced colonic hypersensitivity in stress-naïve adult male rats while a $\mathrm{CRH}_{2}$ antagonist was also able to inhibit stress-induced colonic hypersensitivity (Larauche et al., 2009; Nozu et al., 2014; Mulak et al., 2015). There is strong supportive experimental evidence for an important role for $\mathrm{CRH}$ in chronic visceral hypersensitivity following exposure to early life adversity. In models of early life stress, male mice exposed to maternal separation or neonatal noxious colonic distension developed colonic hypersensitivity in adulthood that was associated with increased $\mathrm{CRH}$ expression within the paraventricular nucleus of the hypothalamus (Zhang et al., 2016a; Tang et al., 2017). In male rats that underwent neonatal noxious colonic distension, adult colonic hypersensitivity was associated with increased $\mathrm{CRH}$ expression in the colon, spinal cord, and brain (Liu H. R. et al., 2015). In another experimental model of ELS in which male pups receive repetitive enemas of dilute acetic acid to induce visceral hypersensitivity in adulthood, intracerebroventricular administration of a nonselective CRH receptor antagonist significantly inhibited adult colonic hypersensitivity (Jia et al., 2013). Thus, dysregulation of $\mathrm{CRH}$ signaling throughout the brain-gut axis can induce colonic hypersensitivity following neonatal and/or adult stressors, emphasizing the importance of this system in the maintenance of chronic visceral pain.

\section{Role of Endocannabinoids in Stress-Induced Visceral Hypersensitivity}

The endogenous endocannabinoids, anandamide and 2-arachidonoylglycerol (2-AG), bind to two G-protein coupled receptors, cannabinoid receptor type $1\left(\mathrm{CB}_{1}\right)$ and type $2\left(\mathrm{CB}_{2}\right)$ (Pertwee et al., 2010; Alexander et al., 2015b). $\mathrm{CB}_{1}$ and $\mathrm{CB}_{2}$ are differentially expressed, with $\mathrm{CB}_{1}$ being the major central receptor that can modulate stress and pain perception, while $\mathrm{CB}_{2}$ is the major peripheral receptor with an unclear role in stress and pain (Gorzalka et al., 2008; Butler and Finn, 2009; Hill and McEwen, 2010; Luongo et al., 2014). In addition to the receptors, drugs that inhibit the major endocannabinoid degrading enzymes, fatty acid amide hydrolase (FAAH) for anandamide and monoacylglycerol lipase (MAGL) for 2-AG, as well as fatty acid binding proteins that carry anandamide and 2-AG, are also therapeutic targets for stress-induced pain (Patel et al., 2017; Woodhams et al., 2017). Evidence for a role of endocannabinoids in visceral hypersensitivity emanates from studies in experimental models. Recently, a novel FAAH, MAGL, or a combined FAAH/MAGL antagonist were investigated in visceral pain models. Only compounds with either FAAH antagonism activity or a dual $\mathrm{CB}_{1} / \mathrm{CB}_{2}$ agonist provided a robust inhibition of colonic hypersensitivity (Sakin et al., 2015). A selective FAAH antagonist completely inhibited acetic acid-induced writhes and significantly inhibited colonic mustard oil-induced writhes in male mice, through a $\mathrm{CB}_{1}$ sensitive mechanism, with no drug effect in FAAH knockout mice (Fichna et al., 2014). A selective MAGL antagonist dosedependently inhibited phenylbenzoquinone-induced writhes in mice, which was reversed by a $\mathrm{CB}_{1}$ antagonist with no effect of a $\mathrm{CB}_{2}$ antagonist; however, the same doses that were effective at reducing visceral pain disrupted short-term memory (Griebel et al., 2015). MAGL knockout mice demonstrated significantly increased writhes in response to acetic acid, which was inhibited by a $\mathrm{CB}_{1}$ antagonist, while repeated dosing of a MAGL inhibitor was able to exacerbate the writhing response in wildtype mice (Petrenko et al., 2014). Based on co-localization within the myenteric plexus, a novel compound acting as both a FAAH and TRPV1 antagonist significantly inhibited protease activated receptor-2-induced colonic hypersensitivity in male mice, although the effect was not reversed by a selective $C_{1}$ antagonist (Bashashati et al., 2017). In rats exposed to repeated stress induced by water avoidance, colonic hypersensitivity was associated with a region specific loss of $\mathrm{CB}_{1}$ expression and increase in TRPV1 expression in C-fibers of L6-S1 DRGs, along with a local increase in 2-AG content and a decrease in FAAH expression within the DRG (Zheng et al., 2015). Intrathecal delivery of small interfering RNA (siRNA) to knockdown DNA methyltransferase 1 prevented the decrease in $\mathrm{CB}_{1}$ expression, while knockdown of the histone acetyltransferase EP300 inhibited the increase in TRPV1 expression, and either siRNA was able to inhibit WAS-induced colonic hypersensitivity (Hong et al., 2015). In female mice, exposure to water avoidance stress increased $\mathrm{CB}_{2}$ mRNA expression within the colon (Aguilera et al., 2013). Taken together, these preclinical findings suggest that modulation of the endocannabinoid system is capable of affecting visceral sensitivity and thus may play a role in the chronic stress-induced visceral pain. There is some very limited clinical evidence supporting abnormalities in the endocannabinoid system in chronic functional GI pain disorders. An interesting pilot study in 12 patients with pain-associated functional dyspepsia showed increased central availability of $\mathrm{CB}_{1}$ receptors, as measured via positron emission tomography scanning, compared to healthy volunteers (Ly et al., 2015). Similarly, in another pilot study of 14 IBS patients compared to seven healthy volunteers, there was a significant decrease in FAAH mRNA from colonic biopsies in the IBS patients suggesting that the endocannabinoid system may play a role in the pathophysiology of IBS (Fichna et al., 2013). Due to the preliminary nature of these clinical studies, additional studies are required in larger cohorts of patients to fully define the role of the endocannabinoid system in functional pain disorders. 


\section{Role of Gamma-Amino Butyric Acid (GABA) in Stress-Induced Visceral Hypersensitivity}

Receptors for GABA are divided into two functional classes: GABA type $A\left(G_{A B A}\right)$ receptors are ionotropic chloride channels, while $\mathrm{GABA}$ type $\mathrm{B}\left(\mathrm{GABA}_{\mathrm{B}}\right)$ receptors are metabotropic G-protein coupled receptors (Bowery et al., 2002; Olsen and Sieghart, 2008; Alexander et al., 2015b,d). Both receptors are expressed in pain and stress-responsive neural circuits with effects on those systems demonstrated through the use of selective agonists and antagonists (Enna and Bowery, 2004; Goudet et al., 2009; Munro et al., 2013; Gunn et al., 2014). In rodent models, oral administration of a Bifidobacterium sp. genetically engineered to produce GABA resulted in the normalization of electrophysiological properties of colonic nociceptors in a model of chronic colonic hypersensitivity (Pokusaeva et al., 2017). Spinal administration of a selective $\mathrm{GABA}_{\mathrm{A} \alpha-2}$ agonist inhibited colonic sensitivity to distension in female rats with a normosensitive colon (Kannampalli et al., 2017a). A similar finding was demonstrated with intrathecal administration of the $\mathrm{GABA}_{\mathrm{A} \alpha-1}$ agonist, muscimol, wherein the response to noxious colonic distension was inhibited in adult, normosensitive female rats (Sengupta et al., 2013). A positive allosteric modulator of the $\mathrm{GABA}_{\mathrm{B}}$ receptor significantly inhibited colonic hypersensitivity to distension following systemic, but not intrathecal, administration in female rats (Kannampalli et al., 2017b). The same compound in male mice significantly inhibited acetic acid-induced writhes following oral administration (Kalinichev et al., 2017). The GABAB receptor was also found to be the target for $\alpha$-conotoxin Vc1.1, which inhibited colonic nociceptive afferent firing as well as the expression of phosphorylated extracellular signal-related kinase, a marker of nociceptive neuronal activation in the dorsal horn of the spinal cord (Castro et al., 2017). Overall, preclinical evidence suggests GABA signaling participates in the maintenance of visceral pain by a loss of inhibitory tone within the spinal cord and/or the central pain matrix. However, lacking in the literature is strong evidence supporting a role of GABA-mediated mechanisms in visceral pain induced by exposure to stress.

\section{Role of Glutamate in Stress-Induced Visceral Hypersensitivity}

As the major excitatory neurotransmitter, glutamate has both fast ionotropic receptors (AMPA, NMDA, and kainate receptors) and slower metabotropic glutamate (mGlu) receptors that are Gprotein coupled (Alexander et al., 2015b,d). Roles for both classes of glutamate receptors in the regulation of acute and chronic pain are well-established (Palazzo et al., 2014; Zhuo, 2017). Another potential therapeutic target to modulate glutamate signaling is the excitatory amino acid transporters (also known as glutamate transporters) that regulate extracellular glutamate concentration (Alexander et al., 2015c). In pre-clinical models, there is a substantial amount of strong data supporting a role for glutamate located at peripheral and central sites in chronic inflammatory- or stress-induced visceral pain. In preclinical models peripheral administration of NMDA antagonists show a dose-dependent reduction in lactic-acid induced writhes
(Hillhouse and Negus, 2016). Moreover, in male mice with post-inflammatory colonic hypersensitivity there was an increase in the expression of the NR1 subunit of NMDA receptors in the colon, and the colonic hypersensitivity could be replicated by enema administration of a glutamate agonist and inhibited by an NMDA receptor antagonist (Qi Q. Q. et al., 2016). In another study, supporting a central site of action, zymosan-induced persistent visceral hypersensitivity was associated with an increase in AMPA receptors within the anterior cingulate cortex, with direct infusion of an AMPA receptor antagonist into the anterior cingulate inhibiting the pain responses (Liu S. B. et al., 2015). In another model of colonic hypersensitivity induced by neonatal mustard oil enema, chronic colonic hypersensitivity in rats was associated with increased AMPA and NMDA receptor expression in the anterior cingulate (Zhou et al., 2014). In a model of persistent colonic hypersensitivity induced colonic anaphylaxis, hypersensitivity was demonstrated as increased synaptic facilitation in the anterior cingulate from the thalamus, which was inhibited by local infusion of an antagonist targeting the NR2B subunit of NMDA receptors (Wang et al., 2015). In mice, a prodrug of a mGlu $2 / 3$ agonist dose-dependently reduced basal colonic sensitivity, inflammation-induced colonic hypersensitivity, and total writhing behaviors (Johnson et al., 2017). Intrathecal administration of suberoylanilide hydroxamic acid, a histone deacetylase inhibitor, at L6-S2 reversed swim stress-induced colonic hypersensitivity thorough changes in mGlu2/3 receptor expression in female rats (Cao et al., 2016). In a similar fashion, estrogen induced colonic hypersensitivity in ovariectomized female rats was inhibited by intrathecal suberoylanilide hydroxamic acid administration through increases in mGlu2 receptor expression in the spinal cord, providing evidence for epigenetic mechanisms perpetuating chronic phenotypes (Cao et al., 2015). In a rat model of postinfective colonic hypersensitivity, post-infection or acute cold restraint stress increased colonic sensitivity was associated with increased vesicular glutamate transporter 3 expression in the L6-S1 dorsal horn (Yang et al., 2015). Adult male rats with pancreatitis-induced visceral hypersensitivity to mechanical and thermal stimulation had the pain behaviors inhibited by peripheral administration of an mGlu receptor agonist (McIlwrath and Westlund, 2015). Clinical evidence supporting a role for glutamate in stress-induced visceral hypersensitivity is very limited and comes from a few studies in patients with IBS. A recent study found increased colonic mucosal expression of NMDA receptors in IBS patients that was correlated with visceral pain scores (Qi et al., 2017). In another study, an acute oral dose of an NMDA receptor antagonist inhibited temporal summation of second pain in response to noxious thermal stimulation (Zhou et al., 2011). In a follow-up study, a sub-set of IBS patients developed visceral and somatic hypersensitivity induced by repetitive noxious stimulation, which was also inhibited by NMDA receptor antagonism (Verne et al., 2012). IBS patients also demonstrated significant improvement in pain scores following a treatment regimen that included a mixed glutamate receptor uptake enhancer, an NMDA receptor antagonist, an antispasmodic, and a probiotic (Mishra et al., 2014). Although an interesting preliminary investigation, the 
interpretation of such a clinical study is difficult based upon the limited size of the study and the non-specific nature of this glutamate reuptake enhancer and NMDA receptor antagonist combination.

\section{ENVIRONMENTAL STRESS IN ADULTHOOD}

Daily life has many stressors, such as finances, illness, or job security, which can be chronic and unpredictable in nature. An individual's response to persistent stressors is, in part, determined by resilience factors, such as social support or underlying genetic polymorphisms (Schilling and Diehl, 2015). However, for vulnerable individuals the inability to adequately cope with chronic stressors can lead to pathological health effects, such as chronic pain syndromes (Gillespie et al., 2009; Leyro et al., 2010). Adults suffering with chronic visceral pain typically have a poor quality of life and require additional healthcare resources to attempt to manage their prolonged visceral pain. Indeed, many sources of chronic pain including stress-induced have been linked to co-morbid psychiatric illnesses such as anxiety and depression, which in turn promote increased pain sensitivity, established a self-reinforcing cycle between chronic stress and chronic pain.

\section{Animal Models to Assess Stress-Induced Visceral Hypersensitivity in Adults}

Since the evaluation of spontaneous pain behaviors is difficult in most animal models, pain from the visceral organs is typically evoked by either distension of a hollow organ (esophagus, stomach, colon, uterus, bladder) or by administration of an irritant via intraperitoneal injection or infusion. In response to the stimulus, visceral nociception can be qualitatively evaluated by scoring nocifensive behaviors (abdominal contractions, facial grimace, stretching, writhing). Quantitative measurements of nociceptive stimuli can be conducted through visual counting, or electromyogenic recording, of the visceromotor response or through the use of von Frey filament withdrawal threshold to probing of the abdomen or pubic areas. Limitations of evaluating nocifensive behaviors include that the acute evoked nociceptive responses may not utilize the same signaling mechanisms as chronic pain behaviors; furthermore, without proper acclimatization, the evoked responses can also initiate stress responses that will also influence sensitivity. Evaluation of qualitative measures should be conducted by blinded observers whenever possible to minimize unconscious bias during the behavioral evaluation. While conditioned place preference testing has been developed in models of somatic pain to evaluate spontaneous behaviors and analgesic properties of new therapeutics, the use of this paradigm to evaluate spontaneous visceral pain in animal models has yet to be validated (Navratilova et al., 2013). Multiple models have been developed to evaluate the effect of acute or chronic stressors on visceral sensitivity in adult animals (Figure 2). The key strength of these models is the ability to directly test causal rather than correlative hypotheses through in vivo behaviors and ex vivo

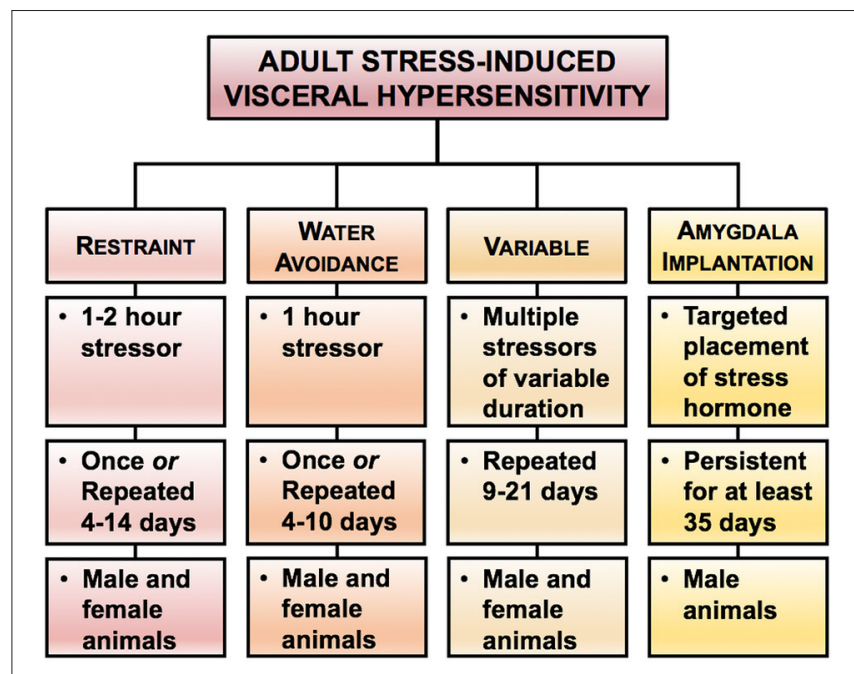

FIGURE 2 | Rodent models of stress-induced visceral hypersensitivity in adult animals. Here we highlight four experimental approaches for increasing visceral sensitivity in adult rodents. In each stress model, we present the duration of the stressor required to produce visceral hypersensitivity and have indicated which sex has been investigated. Please note that the duration and timing of the stressors reflect the range of procedures used within the literature, rather than a specific experimental protocol.

or in vitro assays to determine mechanisms responsible for stress-induced chronic visceral pain. The main limitations of these models are that many have low construct validity (rodent stressors do not typically correspond to human stressors), the effect of sex has not necessarily been addressed in each model, and strain differences can affect the results depending on the type and duration of the stressor used to change sensitivity (Dhabhar et al., 1997; Vendruscolo et al., 2004; Girotti et al., 2006). While there are more comprehensive evaluations of animal models for GI disorders, here we focus on discussing the more commonly used models of stress-induced colonic hypersensitivity (Greenwood-Van Meerveld et al., 2015; Johnson and Greenwood-Van Meerveld, 2017). A comparison of the stress models is presented in Table 1. The overall goal of this table is to allow the reader to compare the various stressors and their impact on visceral pain with an emphasis on the strain and sex of the animal and the duration of the stressor. To our knowledge such a comparison between stress models has not been previously reported. However, due to improved standards of data transparency, we were able to attempt this analysis when extrapolating the mean and the variability of the data from either the text and/or the graphical information within the citation was possible. A limitation of this type of effect size comparison across stress models is that we have only used a subset of the published literature based on the ability to determine group sizes, mean and an error estimate from the mean from the published data.

\section{Restraint Stress}

This model was first demonstrated to induce colonic hypersensitivity to distension following an acute restraint 
TABLE 1 | Comparisons of models to assess stress-induced visceral hypersensitivity in adult animals.

\begin{tabular}{|c|c|c|c|c|}
\hline Species, Strain, Sex & Protocol & Distension stimulus & $\begin{array}{l}\text { Hedges' } d \pm \text { se: } \\
\text { Sham vs. Stress }\end{array}$ & Reference \\
\hline \multicolumn{5}{|l|}{ RESTRAINT STRESS } \\
\hline & $2 \mathrm{~h}$ stress/day, 4 days & $60 \mathrm{mmHg}, 24 \mathrm{~h}$ post-stress & $4.8 \pm 1.0$ & Shen et al., 2010 \\
\hline $\begin{array}{l}\text { Rat, Sprague Dawley, } \\
\text { Female }\end{array}$ & $2 \mathrm{~h}$ stress & $1.2 \mathrm{ml}$ & $5.2 \pm 1.1$ & Zhao et al., 2011 \\
\hline \multirow{2}{*}{ Rat, Wistar, Male } & $2 \mathrm{~h}$ stress/day, 7 days & $60 \mathrm{mmHg}$ & $1.9 \pm 0.7$ & Xu et al., 2014 \\
\hline & $1 \mathrm{~h}$ stress/day, 14 days & $60 \mathrm{mmHg}, 24 \mathrm{~h}$ post-stress & $3.4 \pm 1.0$ & Yi et al., 2014 \\
\hline \multirow[t]{7}{*}{ Rat, Wistar, Female } & $2 \mathrm{~h}$ stress & $1.2 \mathrm{ml}$ & $1.3 \pm 0.6$ & Bradesi et al., 2002 \\
\hline & & & $1.9 \pm 0.6$ & Fioramonti et al., 2003 \\
\hline & & & $1.6 \pm 0.6$ & Ait-Belgnaoui et al., 2005 \\
\hline & & & $0.6 \pm 0.5$ & Eutamene et al., 2010 \\
\hline & & & $1.2 \pm 0.4$ & Silos-Santiago et al., 2013 \\
\hline & & & $2.5 \pm 0.8$ & Gilet et al., 2014 \\
\hline & $2 \mathrm{~h}$ stress/day, 4 days & $1.2 \mathrm{ml}$ & $2.1 \pm 0.6$ & Bradesi et al., 2002 \\
\hline \multicolumn{5}{|c|}{ WATER AVOIDANCE STRESS (WAS) } \\
\hline \multirow[t]{2}{*}{ Mouse, C57BL/6J, Male } & $1 \mathrm{~h}$ stress/day, 4 days & $0.06 \mathrm{ml}$ & $0.8 \pm 0.5$ & Annaházi et al., 2012 \\
\hline & & & $1.2 \pm 0.6$ & Nébot-Vivinus et al., 2014 \\
\hline \multirow[t]{2}{*}{ Rat, Fischer 344, Male } & $1 \mathrm{~h}$ stress & $60 \mathrm{mmHg}$ & $2.0 \pm 0.7$ & $\begin{array}{l}\text { Myers and Greenwood-Van Meerveld, } \\
2012\end{array}$ \\
\hline & $1 \mathrm{~h}$ stress /day, 7 days & $60 \mathrm{mmHg}, 24 \mathrm{~h}$ post-stress & $1.5 \pm 0.7$ & \\
\hline Rat, Long Evans, Female & $1 \mathrm{~h}$ stress/day, 7 days & & $5.9 \pm 1.3$ & \\
\hline \multirow[t]{5}{*}{ Rat, Sprague Dawley, Male } & $1 \mathrm{~h}$ stress & $60 \mathrm{mmHg}, 24 \mathrm{~h}$ post-stress & $0.8 \pm 0.5$ & Watson et al., 2012 \\
\hline & $1 \mathrm{~h}$ stress/day, 10 days & & $1.6 \pm 0.6$ & Hong et al., 2009 \\
\hline & & & $2.9 \pm 0.8$ & Hong et al., 2011 \\
\hline & & & $2.7 \pm 0.8$ & Hong et al., 2015 \\
\hline & & & $2.5 \pm 0.8$ & Zheng et al., 2015 \\
\hline \multirow[t]{12}{*}{ Rat, Wistar, Male } & $1 \mathrm{~h}$ stress & $60 \mathrm{mmHg}$ & $1.4 \pm 0.6$ & Nash et al., 2012 \\
\hline & & $60 \mathrm{mmHg}, 24 \mathrm{~h}$ post-stress & $2.8 \pm 0.6$ & Schwetz et al., 2004 \\
\hline & & & $1.0 \pm 0.5$ & Bradesi et al., 2007 \\
\hline & & & $1.0 \pm 0.5$ & Eutamene et al., 2010 \\
\hline & $1 \mathrm{~h}$ stress /day, 4 days & $60 \mathrm{mmHg}$ & $1.8 \pm 0.6$ & Da Silva et al., 2014 \\
\hline & $1 \mathrm{~h}$ stress/day, 10 days & $60 \mathrm{mmHg}$ & $0.6 \pm 0.3$ & Bradesi et al., 2005 \\
\hline & & & $4.0 \pm 1.1$ & Wang W. et al., 2017 \\
\hline & & $60 \mathrm{mmHg}, 24 \mathrm{~h}$ post-stress & $1.2 \pm 0.6$ & Bradesi et al., 2006 \\
\hline & & & $2.8 \pm 0.9$ & Bradesi et al., 2009 \\
\hline & & & $2.0 \pm 0.6$ & Xu et al., 2014 \\
\hline & & & $1.7 \pm 0.7$ & Tang et al., 2015 \\
\hline & & & $5.1 \pm 0.6$ & Sun et al., 2016 \\
\hline Rat, Wistar, Female & $1 \mathrm{~h}$ stress/day, 10 days & $60 \mathrm{mmHg}, 24 \mathrm{~h}$ post-stress & $4.9 \pm 1.1$ & Gilet et al., 2014 \\
\hline
\end{tabular}


TABLE 1 | Continued

\begin{tabular}{|c|c|c|c|c|}
\hline Species, Strain, Sex & Protocol & Distension stimulus & $\begin{array}{l}\text { Hedges' } d \pm \text { se: } \\
\text { Sham vs. Stress }\end{array}$ & Reference \\
\hline \multicolumn{5}{|l|}{ VARIABLE STRESS } \\
\hline \multirow[t]{5}{*}{ Rat, Sprague Dawley, Male } & 9 days & $60 \mathrm{mmHg}$ & $1.5 \pm 0.6$ & Zhou et al., 2012 \\
\hline & & & $1.2 \pm 0.6$ & Chen et al., 2013 \\
\hline & & & $1.8 \pm 0.6$ & Zhou et al., 2012 \\
\hline & & & $2.7 \pm 0.7$ & Zhang et al., 2014 \\
\hline & 21 days & $1.2 \mathrm{ml}$ & $0.9 \pm 0.5$ & Chen et al., 2009 \\
\hline \multirow[t]{2}{*}{ Rat, Wistar, Male } & 9 days & $60 \mathrm{mmHg}$ & $1.3 \pm 0.4$ & Winston et al., 2010 \\
\hline & & $\begin{array}{l}\text { Area under the curve, } 24 \mathrm{~h} \\
\text { post-stress }\end{array}$ & $2.8 \pm 0.7$ & Winston et al., 2014 \\
\hline & & $60 \mathrm{mmHg}$ & $2.3 \pm 0.7$ & $\begin{array}{l}\text { Myers and Greenwood-Van Meerveld, } \\
2007\end{array}$ \\
\hline & & & $2.6 \pm 0.8$ & $\begin{array}{l}\text { Myers and Greenwood-Van Meerveld, } \\
2010 \mathrm{a}\end{array}$ \\
\hline & & & $2.7 \pm 0.8$ & $\begin{array}{l}\text { Myers and Greenwood-Van Meerveld, } \\
2010 b\end{array}$ \\
\hline & & & $2.5 \pm 0.6$ & Tran et al., 2012 \\
\hline & & & $2.6 \pm 0.8$ & $\begin{array}{l}\text { Johnson and Greenwood-Van } \\
\text { Meerveld, } 2015\end{array}$ \\
\hline & & & $3.4 \pm 0.7$ & Johnson et al., 2015 \\
\hline & 14-day post-implant & $60 \mathrm{mmHg}$ & $2.4 \pm 0.8$ & $\begin{array}{l}\text { Myers and Greenwood-Van Meerveld, } \\
2010 b\end{array}$ \\
\hline
\end{tabular}

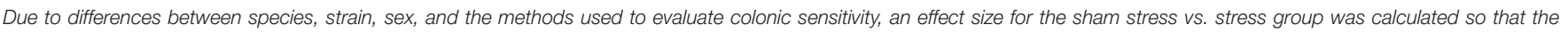

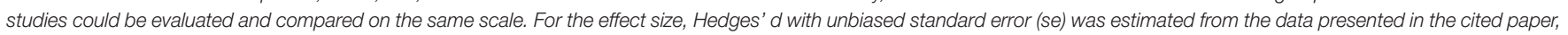

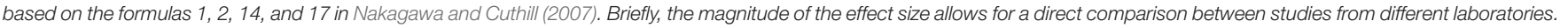

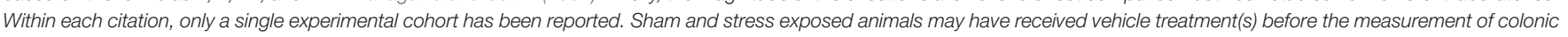
sensitivity.

session (Gué et al., 1997). Subsequently, the protocol has been modified by different researchers to restrain the animal either by wrapping the limbs to hinder walking and grooming or by using a tube or cage that prevents turning and grooming for 1-2 h. While the acute session does not model a chronic stressor, this model can be combined with other stressors to evaluate the effects of multiple "hits" on behavior and colonic sensitivity, or the restraint can be repeated each day to induce a more persistent response in strains that do not habituate to the daily stressor (Girotti et al., 2006). Possible modulators of restraint stress-induced colonic hypersensitivity include: cannabinoid type $1\left(\mathrm{CB}_{1}\right)$ receptors, $\mathrm{CRH}$ receptors, guanylate cyclase$\mathrm{C}$ receptors, neurokinin-1 receptors, neurokinin-3 receptors, nociception/orphanin FQ receptors, protease activated receptors, and serotonin receptors (Gué et al., 1997; Bradesi et al., 2002; Fioramonti et al., 2003; Agostini et al., 2009; Eutamene et al.,
2010; Ohashi-Doi et al., 2010; Shen et al., 2010; Zhao et al., 2011; Silos-Santiago et al., 2013; Gilet et al., 2014). Central neural mechanisms influence the nociceptive response to chronic restraint stress as bilateral insular cortex lesions in rats inhibited the stress-induced colonic hypersensitivity (Yi et al., 2014). At a peripheral level, an interaction between colonic hypersensitivity and colonic permeability was demonstrated by reversal of both stress-induced changes following administration of a tight-junction inhibitor or myosin light chain kinase inhibitor, but not an endothelial cell adhesion molecule inhibitor (Ait-Belgnaoui et al., 2005; Winchester et al., 2009). There is also evidence suggesting a potential role for the microbiome in the development of stress-induced colonic hypersensitivity. However, to date there have been only a limited number of studies investigating the direct interactions of the gut microbiota and its metabolites on restraint stress 
induced pain and nociceptive processes. There is preclinical data showing that antibiotic treatment or administration of specific probiotic genera such as Lactobacillus or Bifidobacterium inhibit partial restraint stress-induced visceral hypersensitivity (Ait-Belgnaoui et al., 2006; Agostini et al., 2012; Xu et al., 2014; Miquel et al., 2016; Darbaky et al., 2017). However, the ability to translate positive preclinical findings with probiotics into effective therapeutics has proven difficult due in part to the huge diversity in the microbiome between rodents and patients.

\section{Water Avoidance Stress (WAS)}

WAS has been used to model both acute and chronic effects of a psychological stressor on colonic sensitivity. The typical procedure is to place the rodent on a platform surrounded by water in an unescapable enclosure for $1 \mathrm{~h}$ per day, either acutely or for 7-10 days (Bradesi et al., 2005; Hong et al., 2009; Tran et al., 2013). Colonic sensitivity to distension is then typically evaluated immediately or $24-\mathrm{h}$ post the final WAS procedure (Eutamene et al., 2010; Myers and Greenwood-Van Meerveld, 2012; Nash et al., 2012; Watson et al., 2012; Tran et al., 2014; Prusator and Greenwood-Van Meerveld, 2016a). Possible modulators of WAS-induced colonic hypersensitivity include: $\mathrm{CRH}$ receptors, dopamine-2 receptors, guanylate cyclase-C receptors, potassium chloride co-transporter, protease activated receptor- 4 , neurokinin- 1 receptors, serotonin receptors, transient receptor potential cation channel subfamily $\mathrm{V}$ member 1 (TRPV1) receptors, and vasopressin-3 receptor (Schwetz et al., 2004; Bradesi et al., 2006, 2007, 2009; Eutamene et al., 2010; Annaházi et al., 2012; Nash et al., 2012; Gilet et al., 2014; Tang et al., 2015; Sun et al., 2016). Within limbic brain circuits, glucocorticoid receptor (GR), mineralocorticoid receptor (MR) and CRH mediate WASinduced colonic hypersensitivity (Myers and Greenwood-Van Meerveld, 2012; Tran et al., 2013, 2014; Johnson et al., 2015). In the dorsal root ganglia that innervate the distal colon, epigenetic mechanisms differentially affect expression of GR, $\mathrm{CB}_{1}$, and TRPV1 to induce colonic hypersensitivity following WAS (Hong et al., 2009, 2011, 2015). Through the use of antibiotics, prebiotics, probiotics, and anti-fungal agents, there is preclinical evidence supporting a role for microbiota to inhibit WAS-induced colonic hypersensitivity (Da Silva et al., 2014; Nébot-Vivinus et al., 2014; Xu et al., 2014; Botschuijver et al., 2017; Wang W. et al., 2017). Recently, WAS has been used as a model of stress-induced bladder pain to investigate mechanisms of visceral pain associated with interstitial cystitis or bladder pain syndrome (Lee et al., 2015; Ackerman et al., 2016; Matos et al., 2017; Wang Z. et al., 2017).

\section{Variable Stress}

Both restraint and water avoidance are homotypic stressors, and some rodent strains will adapt to repeated stress exposure. To prevent adaptation, rodent models termed, heterotypic intermittent stress or heterotypic chronic stress (HeCS), have been developed in which the animals are exposed to variable stressors (cold restraint, water avoidance, or forced swim) presented randomly over multiple days to induce persistent colonic hypersensitivity. While used less frequently, these stress paradigms have demonstrated roles for $\beta_{2}$ adrenergic receptors, brain-derived neurotrophic factor, cystathionine $\beta$-synthetase, endorphins, and nerve growth factor in the stress-induced colonic hypersensitivity (Winston et al., 2010, 2014; Wang et al., 2012; Zhou et al., 2012; Chen et al., 2013; Zhang et al., 2014). Additional models of chronic variable stress implicated mast cell mediators and toll-like receptor 4 signaling as factors induced by stress to promote chronic colonic hypersensitivity (Chen et al., 2009; Tramullas et al., 2014).

\section{Amygdala Implantation}

Manipulation of limbic brain circuitry that integrates stress and pain processing is sufficient to change colonic sensitivity in rats. In our team, we have stereotaxically targeted the CeA with CORT micropellets to induce colonic hypersensitivity to distension and anxiety-like behavior (Greenwood-Van Meerveld et al., 2001). After 7 days of exposure of the CeA to the CORT micropellet, there is also increased blood-oxygen utilization in response to colonic distension throughout the brain, which is similar to heightened brain activation induced by colonic distension in IBS patients (Naliboff et al., 2003; Wilder-Smith et al., 2004; Johnson et al., 2010). Mechanistically, there are non-redundant roles for both GR and MR signaling and CRH type $1\left(\mathrm{CRH}_{1}\right)$ receptors mediating the persistent colonic hypersensitivity (Myers and Greenwood-Van Meerveld, 2007, 2010a,b; Johnson et al., 2012; Tran et al., 2012). Furthermore, directly manipulating GR, $\mathrm{MR}$, or CRH expression within the CeA had a profound effect on colonic sensitivity illustrating the importance of the $\mathrm{CeA}$ in visceral pain processing (Johnson and Greenwood-Van Meerveld, 2015; Johnson et al., 2015). Chronic changes in GR and $\mathrm{CRH}$ expression following the CORT micropellet implantation on the CeA were induced by an epigenetic mechanism involving deacetylation of the GR promoter causing increases in CRH expression, leading to the chronic colonic hypersensitivity (Tran and Greenwood-Van Meerveld, 2012; Tran et al., 2015). Thus, central dysfunction of limbic circuity induces colonic hypersensitivity without manipulation of the colon.

\section{RELATIONSHIP BETWEEN EARLY LIFE STRESS (ELS) AND CHRONIC VISCERAL PAIN IN LATER LIFE}

Early childhood is a pivotal period for the development of the specific brain circuitry regulating stress and nociception. In the United States, at least 1 in 10 children will experience some form of physical and/or psychological abuse that will bias the development of their pain neurocircuitry toward enhanced pain perception in adulthood (Anda et al., 2006; Bradford et al., 2012). The "multiple hit" model has gained popularity to explain how the complex interaction between genetic and epigenetic risk factors and adverse childhood experiences (early life stresses) induce adult pathologies such as mood disorders or the development of chronic pain. With the first "hit" being in utero development or genetic predisposition, ELS before puberty acts as a second "hit" to cause maladaptation of the stress axis 
to stressors that can predispose the individual to heightened pain perception. During puberty (potentially a third "hit"), the surge of hormones, especially estrogen and progesterone, further sensitizes stress and pain circuitry promoting the development of functional visceral pain disorders such as IBS in adulthood (Meleine and Matricon, 2014). Each "hit," such as abuse, parental care, poor diet, psychological disorders, or social stressors, drives the stress and pain circuitry toward persistent sensitization leading to IBS symptomology due to a dysregulation of the brain-gut axis (Miranda and Saps, 2014).

\section{Animal Models to Assess ELS-Induced Visceral Hypersensitivity}

Animal models have provided evidence that pain in early life is capable of priming nerves to be more excitable in response to nociceptive stimuli in adulthood (Beggs et al., 2012). Due to the variety of ELS models, the mechanism underlying the development of chronic visceral pain in adulthood will be influenced by the type, duration, and developmental timing of the initial insult. While most of the ELS models induce chronic visceral hypersensitivity, the nature of the ELS (modeling neglect, poverty, or abuse) produces chronic, sexually dimorphic changes in behaviors that can be exploited to model different life experiences in adulthood in patients with chronic abdominal pain (Figure 3) (Prusator and GreenwoodVan Meerveld, 2016b). A comparison of the ELS models discussed below is presented in Table 2 with the same caveats as previously described for Table 1.

\section{Maternal Separation (MS)}

Adult male rats exposed to MS as neonates develop colonic hypersensitivity to distension or display colonic hypersensitivity following an adult stressor (second "hit") (Coutinho et al., 2002; Rosztóczy et al., 2003; van den Wijngaard et al., 2009, 2012; Stanisor et al., 2013). MS models neglect through the prolonged separation of the dam from the pups. Upon return of the pups, the dam's behavior is altered such that the quality of care is reduced, which primes aberrant responses of the HPA axis.

\section{Limited Nesting}

In an attempt to model impoverished care in early life, rodents are exposed to a nest with reduced bedding material (Drake and Pandey, 1996). Without adequate resources to build a nest for her pups, the quality of the dam's care for the pups is abnormal causing abnormal activation of the HPS axis that persists into adulthood (Gilles et al., 1996; Avishai-Eliner et al., 2001). Following exposure to limited nesting as neonates, colonic hypersensitivity is predominantly seen in adult males (Prusator and Greenwood-Van Meerveld, 2015, 2016b; Holschneider et al., 2016). There is also evidence for altered connectivity and function (CRH and GR expression) of limbic and pain circuits in adult rats exposed to limited nesting (Avishai-Eliner et al., 2001; Ivy et al., 2008; Rice et al., 2008; Holschneider et al., 2016).

\section{Odor-Attachment Learning}

Using a classical conditioning paradigm, the odor-attachment learning paradigm attempts to model attachment to an abusive

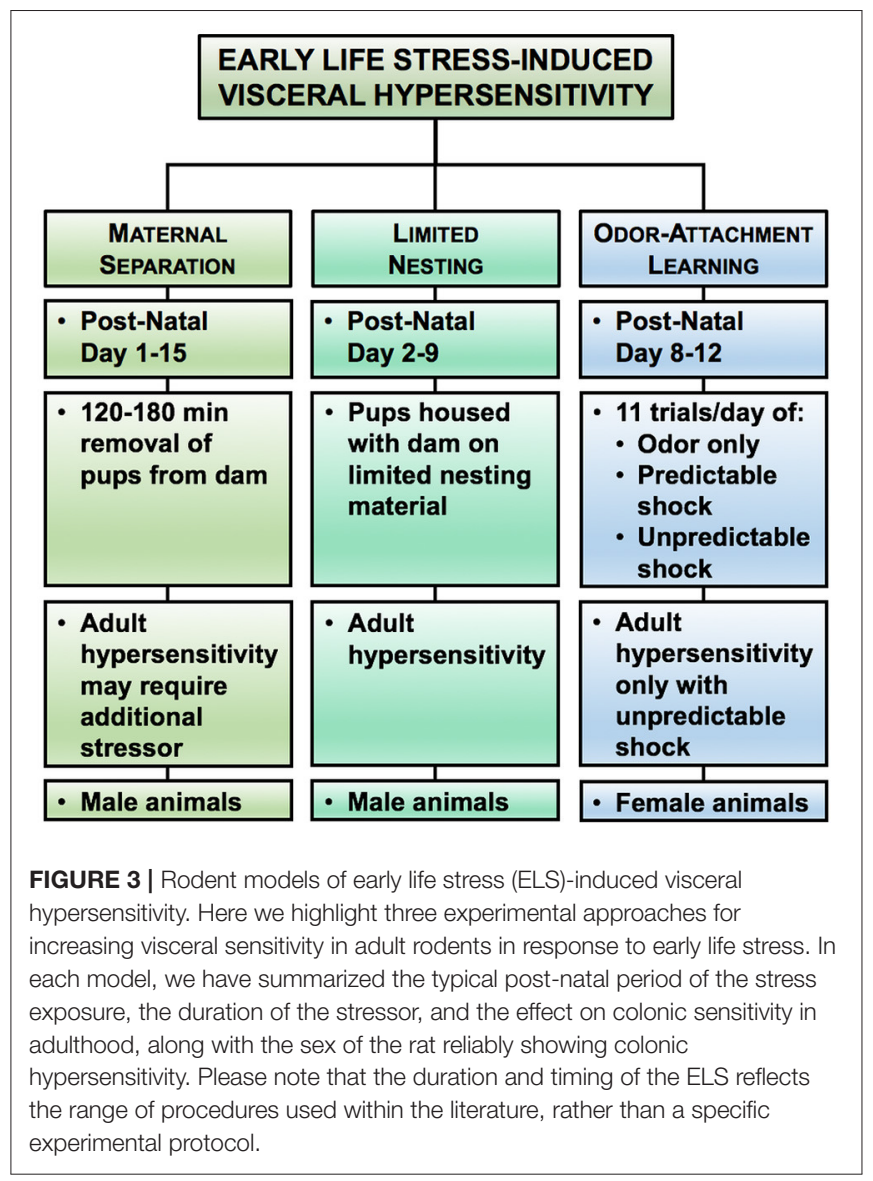

caregiver by exposing the neonatal pups to predictable or unpredictable odor-shock pairings (Sullivan et al., 2000; Tyler et al., 2007; Sevelinges et al., 2011). The odor-attachment learning model exploits the stress hyporesponsive period in the neonatal pups (post-natal day 8-12) to induce an attachment to the conditioning odor in the predictable shock group without causing the pups to form an association or an aversion to conditioning odor in the unpredictable shock group (Camp and Rudy, 1988; Moriceau and Sullivan, 2004; Moriceau et al., 2006). Only female rats exposed to unpredictable shock develop an estrogen-dependent colonic hypersensitivity, whereas colonic sensitivity in the female rats in the predictable shock and odor only control groups and in all male pups regardless of conditioning exposure resemble normosensitive rats (Chaloner and Greenwood-Van Meerveld, 2013; Prusator and GreenwoodVan Meerveld, 2016b). In addition to systemic estrogen, colonic hypersensitivity in the female rats exposed to unpredictable shock is mediated by GR and CRH activation of $\mathrm{CRH}_{1}$ within the CeA (Prusator and Greenwood-Van Meerveld, 2017). Interestingly, female rats in both the predictable and unpredictable shock groups demonstrate a similar hypersensitive response to colonic distension after a chronic stressor, suggesting that the chronic stress induces a phenotypic switch from resilient to vulnerable in the predictable shock group (Prusator and Greenwood-Van Meerveld, 2016a). 
TABLE 2 | Comparisons of models to assess early life stress (ELS)-induced visceral hypersensitivity in adult animals.

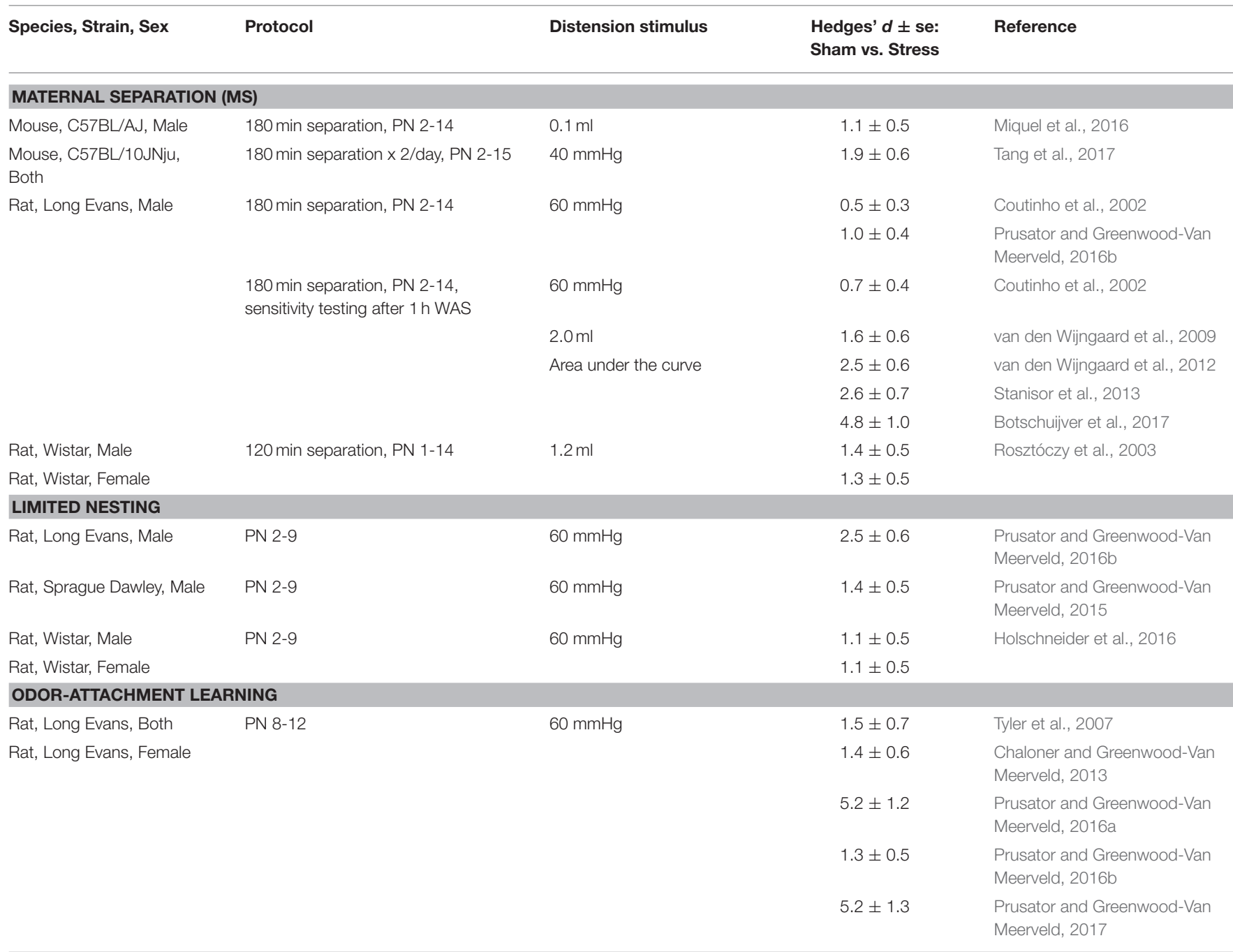

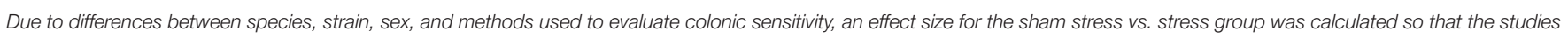

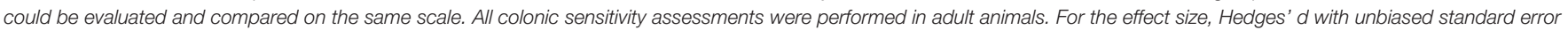

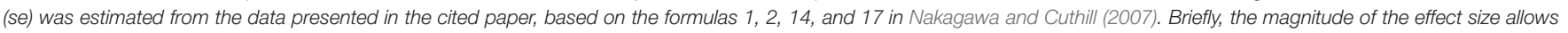

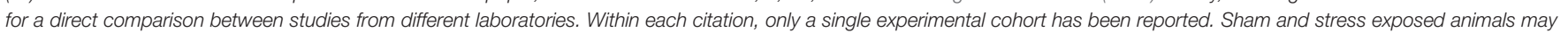
have received vehicle treatment(s) before the measurement of colonic sensitivity. PN, post-natal day.

\section{SEX-LINKED DIFFERENCES IN STRESS-INDUCED VISCERAL PAIN SENSITIVITY}

Within the United States, female patients receive a diagnosis of IBS and other functional pain disorders at twice the rate of males (Chial and Camilleri, 2002; Chang et al., 2006; Heitkemper and Jarrett, 2008). One factor that may explain the increased incidence in females is that gastrointestinal symptoms, such changes in bowel habits, bloating and abdominal pain, are affected by hormone fluctuations during the menstrual cycle (Laessle et al., 1990; Whitehead et al., 1990; Kane et al., 1998). While clinical studies support a role for sex hormones interacting with IBS symptomology, mechanistic studies that provide evidence for specific signaling pathways mediating visceral pain in females are lacking (Ouyang and Wrzos, 2006; Heitkemper and Chang, 2009). A history of early life adversity is an additional factor that may contribute to the increased diagnosis of IBS in females (Drossman et al., 1990; Talley et al., 1994; Bradford et al., 2012). In response to colorectal distension, female IBS patients typically report lower thresholds for pain/discomfort or more pain at similar distension pressures compared to their male counterparts with IBS (Adeyemo et al., 2010; Meleine and Matricon, 2014). Functional imaging studies have been conducted in an attempt to identify sex differences between healthy volunteers and IBS patients. A summary of imaging studies in response to colorectal distension found consistent abnormalities in activation of the amygdala, insula, cingulate, and prefrontal cortex between IBS patients and healthy volunteers (Weaver et al., 2016). Similarly, in IBS patients, 
females demonstrated altered amygdala and cingulate activation compared to males (Naliboff et al., 2003). A newer modality in brain imaging is the analysis of resting state functional connectivity which aims to identify default networks influencing behaviors and pain perception. In studies comparing resting state functional connectivity in IBS patients to healthy controls, significant alterations in amygdala connections between the insula and other cortical regions, altered cingulate-cortical connections, and alterations in amygdala-insula and cingulatethalamic connections were found to be specific to females with IBS and visceral hypersensitivity (Ma et al., 2015; Qi, R. et al., 2016; Weng et al., 2016; Icenhour et al., 2017). Additionally, a history of ELS influences resting state functional connectivity in both male and female IBS patients (Gupta et al., 2014). Overall, these imaging studies verify that the central pain matrix is differentially activated in females and males with regard to visceral sensation, in part due to the influence of sex hormones on neuronal sensitivity (Chang et al., 2006; Voß et al., 2013). Animal data support these clinical observations. Specifically, female animals display increased colonic sensitivity following stress exposure in comparison to male animals (Kayser et al., 1996; Chaloner and Greenwood-Van Meerveld, 2013). Furthermore, the phase of the estrus cycle can affect colonic sensitivity in female rodents, with hypersensitivity during proestrus/estrus phases with high circulating estrogen and progesterone vs. diestrus/metestrus with the lowest circulating hormone levels (Sapsed-Byrne et al., 1996; Ji et al., 2008). The ability to recapitulate clinical observations in experimental models will provide a foundation for future studies investigating the basic mechanisms underlying stress-induced visceral hypersensitivity.

In female rats the central mechanisms modulating visceral hypersensitivity have been investigated in experimental models. Elevating amygdala CORT with stereotaxically placed micropellets on the $\mathrm{CeA}$, we have observed colonic hypersensitivity during diestrus or following ovariectomy, but not during proestrus (Gustafsson and Greenwood-Van Meerveld, 2011). Furthermore, in ovariectomized female or male rats, stereotaxic implantation onto the CeA of micropellets containing estrogen or progesterone induced colonic hypersensitivity (Gustafsson and Greenwood-Van Meerveld, 2011; Myers et al., 2011). Aside from its reproductive role, estrogen is a key mediator of brain development and plays a role in plasticity in nociceptive circuits (Handa et al., 1994; Fitch and Denenberg, 1998). For example, within the medial amygdala, estrogen causes $\mu$-opioid receptor internalization and within nociceptive circuitry estrogen can compete with GR to affect CRH signaling to promote increased sensitivity to peripheral sensations (Vamvakopoulos and Chrousos, 1993; Uht et al., 1997; Eckersell et al., 1998; Miller et al., 2004). At the level the dorsal horn of the spinal cord, estrogen can modify expression and function of NMDA receptors and mGlu2 receptors to effect ascending visceral pain signaling (Tang et al., 2008; Cao et al., 2015; Ji et al., 2015). In females, estrogen-induced changes in glutamate receptor function can promote the sensitization of the nociceptive circuits to induce or exacerbate colonic hypersensitivity. These same mechanisms amplifying colonic hyperalgesia can be invoked in male rodents through the exogenous administration of estrogen (Aloisi and Ceccarelli, 2000; Aloisi and Bonifazi, 2006). In summary, while the interactions between sex hormones and pain circuitry is complex, steroid hormones can promote the development of chronic hypersensitivity and likely contribute to the sexual dimorphism observed in patients with functional pain disorders such as IBS. Moreover, while sex hormones can contribute to enhanced pain signaling, other factors such as individual differences in stress exposure and coping behaviors, socioeconomic factors, and genetic predisposition contribute to the development of chronic visceral pain (Heitkemper and Jarrett, 2008; Meleine and Matricon, 2014).

\section{EPIGENETIC MECHANISMS MEDIATING STRESS-INDUCED CHRONIC VISCERAL PAIN}

While polymorphisms or random mutations within a genotype can bias an individual toward pathophysiology, the contribution of the environment will ultimately determine the resilience or vulnerability to stress-induced visceral pain by affecting how genes are expressed. Following the resolution of an injury, many patients suffer from chronic visceral pain suggesting that epigenetic mechanisms may play a role in the persistent nature of the pain. Epigenetics describes variations in phenotype expression due to environmental influences in the absence of mutations within the genomic DNA (Waddington, 1942). While modifications to chromatin, such as acetylation or methylation of histones, are the most studied epigenetic mechanisms, modification of the DNA bases leading to enhanced or repressed transcription also influence overall gene expression (Bernstein et al., 2007). The definition of epigenetics has been expanded to include regulatory RNA sequences (microRNA [miRNA] or small non-coding RNA) due to their ability to affect mRNA translation (Farh et al., 2005; Zhang and Banerjee, 2015). While epigenetic mechanisms have been identified in some chronic neuropathic or inflammatory pain disorders, epigenetic regulation of chronic visceral pain is still an emerging field of research interest (Greenwood-Van Meerveld et al., 2016; Ligon et al., 2016). Histone acetylation and DNA methylation are the other epigenetic mechanisms that can induce persistent changes in gene expression throughout pain circuitry to promote chronic visceral pain (Figure 4). In the first report of an epigenetic regulation of stress-induced visceral pain, we found in male rats that following repeated exposure to a water avoidance stress paradigm there were multiple epigenetic changes within the $\mathrm{CeA}$ including an increased methylation of the glucocorticoid receptor (GR) promoter region and decreased methylation of the CRH promoter region, combined with a decrease in GR mRNA expression and an increase in CRH mRNA expression (Tran et al., 2013). Concurrent with the stress-induced changes in DNA methylation, daily intracerebroventricular administration of the histone deacetylase inhibitor trichostatin A during the stress exposure inhibited the stress-induced colonic hypersensitivity (Tran et al., 2013). These findings provide evidence that repeated psychological stressors induce 


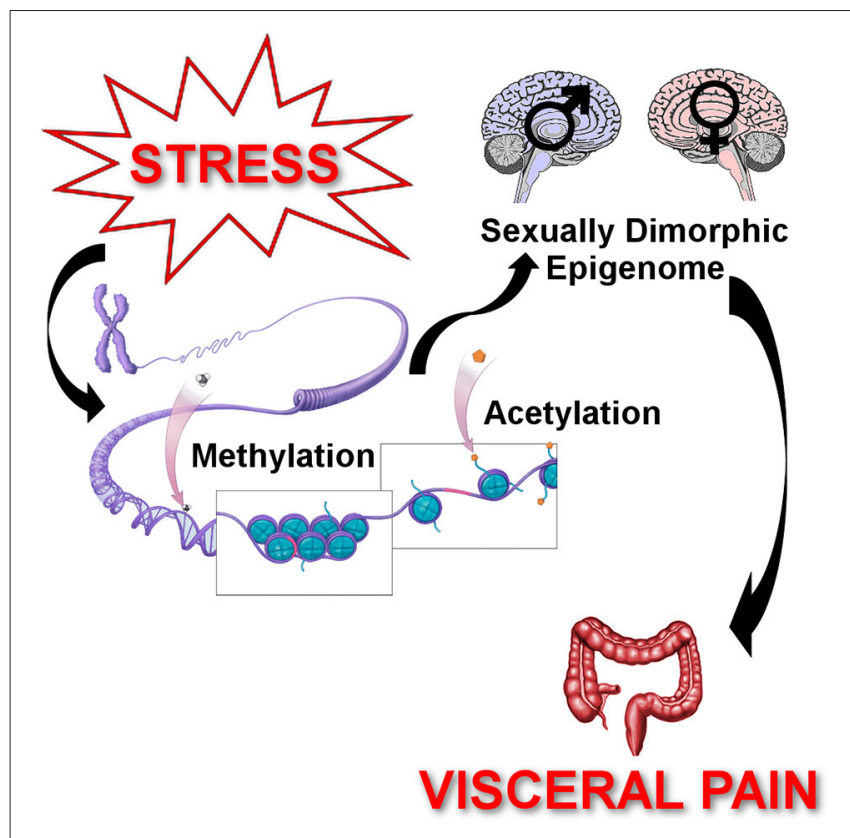

FIGURE 4 | Epigenetic regulation of chronic stress-induced visceral pain. Epigenetics describes the processes by which the environment influences gene expression to cause persistent changes in behaviors. Stressors (early life stress, adult stressors, or both) induce changes in the methylation status of DNA promoter regions to enhance or repress transcription rates. Stressors also change the state of histone acetylation around the gene promoter regions to facilitate or hinder the binding of the transcription complex, which also affects gene transcription. These stress-induced changes in DNA methylation and histone acetylation cause changes in gene expression that persist well beyond the duration of the stressor. Additionally, due to hormonal differences across the lifespan, sex differences in response to stressors can also modify the epigenetically induced changes in gene expression. The net effect is the development of chronic visceral pain following stressors that persist through the individual's lifetime due to epigenetically induced changes in gene expression leading to enhanced neuronal sensitivity.

changes in brain circuits that integrate stress and pain signaling through epigenetic mechanisms. Building upon these initial findings, we found that colonic hypersensitivity induced by elevated amygdala corticosterone (CORT) was associated with persistent decreases in GR expression and persistent increases in $\mathrm{CRH}$ expression within the CeA (Tran and GreenwoodVan Meerveld, 2012). In our subsequent investigation of the epigenetic mechanisms responsible for the persistent colonic hypersensitivity and changes in gene expression, we used chromatin immunoprecipitation assays to show that the reduction in GR expression in the $\mathrm{CeA}$ was due a decrease in acetylation of histone-3 at lysine-9 (ac-H3K9) at the GR promoter, leading to a reduction of GR expression (Tran et al., 2015). With this loss of GR there was a reduction in its binding to a negative response element in the $\mathrm{CRH}$ promoter, permitting an increase in AP-1 binding to a positive regulatory element thereby increasing $\mathrm{CRH}$ expression within the CeA (Tran et al., 2015). Furthermore, the loss of ac-H3K9 could be due to increase activity of the histone deacetylase sirtuin- 6 that was recruited to the GR promoter region by CORT-induced nuclear factor kappa B signaling (Tran et al., 2015). Intra-CeA infusions of trichostatin A or suberoylanilide hydroxamic acid inhibited the CORT-induced colonic hypersensitivity by restoring ac-H3K9 at the GR promoter to prevent the decrease in GR expression (Tran et al., 2015). In another study, Hong and coworkers investigated whether peripheral epigenetic mechanisms play any role in stress-induced visceral hypersensitivity. Following exposure to the water avoidance stress paradigm, analysis of isolated L6S2 dorsal root ganglia (DRG) revealed increased methylation of the GR promoter region due to increased expression of DNA methyltransferase 1 . Together these changes led to a decrease in GR expression and a downregulation of cannabinoid type 1 receptor $\left(\mathrm{CB}_{1}\right)$, which has positive glucocorticoid response elements upstream of the transcription start site, with specific binding verified by chromatin immunoprecipitation assay (Hong et al., 2015). Additionally, there was a specific increase in acetylation of histone 3 around the TRPV1 promoter, due to increased expression of the histone acetyltransferase EP300, leading to increased expression of TRPV1 within the L6S2 DRG (Hong et al., 2015). Building upon these findings, the same team showed that systemic administration of a GR antagonist or intrathecal administration of siRNA targeting DNA methyltransferase 1, EP300, or TRPV1 attenuated WASinduced colonic hypersensitivity. Conversely, siRNA targeting $\mathrm{CB}_{1}$ was found to induce colonic hypersensitivity in nonstressed rats (Hong et al., 2015). Further support for epigenetic mechanisms in stress-induced visceral hypersensitivity in female rats showed that intrathecal suberoylanilide hydroxamic acid administration inhibited stress-induced colonic hypersensitivity through increases in expression of the mGlu2 receptor within the lumbosacral spinal cord due to specific increases in ac-H3K9 upstream of the transcriptional start site for the $\mathrm{mGlu} 2$ receptor (Cao et al., 2015, 2016).

Adverse early environmental experiences, such as abuse, neglect, or sexual trauma, are risk factors for the development of chronic visceral pain disorders through epigenetic remodeling of pain pathways (Bradford et al., 2012; Liu et al., 2017). Although the epigenetic mechanism was not identified, maternal separation (MS)-induced susceptibility to stress-induced colonic hypersensitivity could be transmitted to the F2 generation (van den Wijngaard et al., 2013). In a similar model of MS, peripheral administration of suberoylanilide hydroxamic acid inhibited the MS-induced increase in pain behaviors to distension and increased acetylation of histone- 4 at lysine-12 in the L5-S2 spinal cord (Moloney et al., 2015). In a two "hit" model of post-inflammatory early life stress, colonic hypersensitivity was induced by neonatal and adult colonic inflammation, which caused an increase in brain-derived neurotrophic factor (BDNF) expression in the lumbosacral spinal cord due to increases in acH3K9 and acetylation of histone-4 at lysine-12 (Aguirre et al., 2017). In another important preclinical study performed by Winston and colleagues, rat dams were exposed to HeCS for the final 10 gestational days and then the HeCS protocol was repeated in the adult offspring. Both male and female offspring of HeCS dams were hypersensitive to distension in adulthood, and while both sexes showed an exacerbation of colonic hypersensitivity immediately following the HeCS protocol, only female offspring developed a persistent colonic hypersensitivity (Winston et al., 
2014). Furthermore, in female rats exposed to HeCS from dams that underwent $\mathrm{HeCS}$, there was increased expression of BDNF due to increased ac-H3K9 of the BDNF promoter. These changes in expression and colonic hypersensitivity were inhibited by intrathecal dosing of histone acetyltransferase inhibitors (Winston et al., 2014).

Clinical samples from patients with visceral pain have focused on miRNA targets due to their potential to serve as clinical biomarkers. Whole blood samples from IBS patients and controls identified miR-150 and miR-342-3p as differentially expressed with the potential to affect pain signaling pathways (Fourie et al., 2014). In another study, biopsies from diarrhea-predominate IBS patients found that miR-29 expression positively correlated with increased colonic permeability. Although visceral sensitivity was not evaluated, increased permeability could potentially promote peripheral and central sensitization leading to increased visceral hypersensitivity (Zhou et al., 2010, 2015; Zhou and Verne, 2011; Camilleri et al., 2012). Colonic biopsy samples from IBS patients were also found to have increased expression of miR-24 (Liao et al., 2016), however its role in stress-induced visceral pain remains to be studied. As a negative regulator of transient receptor potential cation channel subfamily $\mathrm{V}$ member 1 (TRPV1) expression, miR-199 expression in colonic biopsies was negatively correlated with visceral pain scores and TRPV1 expression in diarrhea-predominate IBS patients (Zhou Q. et al., 2016). Preclinical studies in rat models examined miRNA expression in the spinal cord and identified miR-17$5 \mathrm{p}$ as a possible mediator of water avoidance stress-induced colonic hypersensitivity (Sengupta et al., 2013; Bradesi et al., 2015; Zhang et al., 2017). In summary, life experiences along with a person's genetic make-up determines their vulnerability or resilience to developing chronic stress-induced pain disorders such as IBS. The interactions between genes and environments, termed epigenetics, influence long-term stress reactivity and pain sensitivity which can lead to the development of pathophysiology with each "hit" received by an individual.

\section{SUMMARY AND CONCLUSION}

Patients suffering from chronic visceral pain experience a significant reduction in their quality of life, utilize more healthcare resources, and have few therapeutic options. Visceral pain can be initiated from the "bottom-up" by a disturbance within the periphery such as an infection or injury, or could be initiated from the "top-down" by a pathophysiologic response to severe or repeated stressors. Indeed, there is significant overlap of neural circuity that process sensations of pain or stress, such as the amygdala, the insula, or areas of the cingulate, along with common neurotransmitters and their receptors, such as GR or $\mathrm{CRH}$, that are expressed within the GI tract on

\section{REFERENCES}

Ackerman, A. L., Jellison, F. C., Lee, U. J., Bradesi, S., and Rodriguez, L. V. (2016). The Glt1 glutamate receptor mediates the establishment and perpetuation of chronic visceral pain in an animal model of stress-induced resident immune cells or intrinsic nerves and within dorsal root ganglia, the spinal cord, and throughout the brain. The major neuroendocrine stress hormone, CORT, which is secreted in response to activation of the HPA axis by stressors, acts at GR and MR receptors throughout the body, but can also promote enhanced sensitivity of neurons to both noxious and innocuous stimuli, which in turn promotes the development of chronic pain. In addition to their chronic pain disorder, patients may have reduced coping skills to typical life stressors. To investigate the mechanisms and identify new therapeutics for chronic visceral pain, multiple animal models of stress-induced colonic hypersensitivity have been developed. While each model employs a different adult stressor (physical, psychological, or both), applied for different durations and/or repetitions, these various experimental approaches induce consistent visceral hypersensitivity in rodent models. An additional and important risk factor for the development of chronic visceral pain is exposure to early life adverse environments, such as abuse, neglect, or poverty. These early life stressors are thought to prime the developing stress and pain circuity within the nervous system to become sensitized in response to stimuli. Rodent models have been used to model specific aspects of early life stress to identify vulnerability and resilience factors depending on whether the adult animal develops chronic colonic hypersensitivity. Sex is also a significant factor in the development of chronic stressinduced pain. Females are twice as likely to be diagnosed with a chronic visceral pain disorder, and are more likely to have a history of early life stress. Moreover, since sex hormones can modulate neuronal sensitivity and synaptic connections, females may have a biological bias toward chronic visceral pain. Finally, epigenetics are the tools the body uses to imprint positive and negative environmental experiences onto the genotype of an individual to produce persistent phenotypes. The overall resilience or vulnerability of an individual is the net effect of epigenetic processes that can promote or dampen pain sensitivity, stress reactivity, and coping with adversity to either result in a healthy individual or one that suffers from chronic visceral pain in response to a lifetime of stressors.

\section{AUTHOR CONTRIBUTIONS}

Both authors made a substantial, direct and intellectual contribution to the work, and approved it for publication.

\section{ACKNOWLEDGMENTS}

BG-VM is a Senior Research Career Scientist with the Department of Veterans Affairs (Award \#BX003610). ACJ is a Career Development Awardee with the Department of Veterans Affairs (Award \#BX003630). bladder hyperalgesia. Am. J. Physiol. Renal Physiol. 310, F628-F636. doi: 10.1152/ajprenal.00297.2015

Adeyemo, M. A., Spiegel, B. M., and Chang, L. (2010). Meta-analysis: do irritable bowel syndrome symptoms vary between men and women? Aliment. Pharmacol. Ther. 32, 738-755. doi: 10.1111/j.1365-2036.2010.04409.x 
Agostini, S., Eutamene, H., Broccardo, M., Improta, G., Petrella, C., Theodorou, V., et al. (2009). Peripheral anti-nociceptive effect of nociceptin/orphanin FQ in inflammation and stress-induced colonic hyperalgesia in rats. Pain 141, 292-299. doi: 10.1016/j.pain.2008.12.007

Agostini, S., Goubern, M., Tondereau, V., Salvador-Cartier, C., Bezirard, V., Leveque, M., et al. (2012). A marketed fermented dairy product containing Bifidobacterium lactis CNCM I-2494 suppresses gut hypersensitivity and colonic barrier disruption induced by acute stress in rats. Neurogastroenterol. Motil. 24, 376-e172. doi: 10.1111/j.1365-2982.2011.01865.x

Aguilera, M., Vergara, P., and Martinez, V. (2013). Stress and antibiotics alter luminal and wall-adhered microbiota and enhance the local expression of visceral sensory-related systems in mice. Neurogastroenterol. Motil. 25, e515-e529. doi: 10.1111/nmo.12154

Aguirre, J. E., Winston, J. H., and Sarna, S. K. (2017). Neonatal immune challenge followed by adult immune challenge induces epigenetic-susceptibility to aggravated visceral hypersensitivity. Neurogastroenterol. Motil. 29:e13081. doi: $10.1111 /$ nmo.13081

Ait-Belgnaoui, A., Bradesi, S., Fioramonti, J., Theodorou, V., and Bueno, L. (2005). Acute stress-induced hypersensitivity to colonic distension depends upon increase in paracellular permeability: role of myosin light chain kinase. Pain 113, 141-147. doi: 10.1016/j.pain.2004.10.002

Ait-Belgnaoui, A., Han, W., Lamine, F., Eutamene, H., Fioramonti, J., Bueno, L., et al. (2006). Lactobacillus farciminis treatment suppresses stress induced visceral hypersensitivity: a possible action through interaction with epithelial cell cytoskeleton contraction. Gut 55, 1090-1094. doi: 10.1136/gut.2005.084194

Alexander, S. P., Cidlowski, J. A., Kelly, E., Marrion, N., Peters, J. A., Benson, H. E., et al. (2015a). The concise guide to PHARMACOLOGY 2015/16: nuclear hormone receptors. Br. J. Pharmacol. 172, 5956-5978. doi: 10.1111/bph.13352

Alexander, S. P., Davenport, A. P., Kelly, E., Marrion, N., Peters, J. A., Benson, H. E., et al. (2015b). The concise guide to PHARMACOLOGY 2015/16: G proteincoupled receptors. Br. J. Pharmacol. 172, 5744-5869. doi: 10.1111/bph.13348

Alexander, S. P., Kelly, E., Marrion, N., Peters, J. A., Benson, H. E., Faccenda, E., et al. (2015c). The concise guide to PHARMACOLOGY 2015/16: transporters. Br. J. Pharmacol. 172, 6110-6202. doi: 10.1111/bph.13355

Alexander, S. P., Peters, J. A., Kelly, E., Marrion, N., Benson, H. E., Faccenda, E., et al. (2015d). The concise guide to PHARMACOLOGY 2015/16: ligand-gated ion channels. Br. J. Pharmacol. 172, 5870-5903. doi: 10.1111/bph.13350

Almeida, T. F., Roizenblatt, S., and Tufik, S. (2004). Afferent pain pathways: a neuroanatomical review. Brain Res. 1000, 40-56. doi: 10.1016/j.brainres.2003.10.073

Aloisi, A. M., and Bonifazi, M. (2006). Sex hormones, central nervous system and pain. Horm. Behav. 50, 1-7. doi: 10.1016/j.yhbeh.2005.12.002

Aloisi, A. M., and Ceccarelli, I. (2000). Role of gonadal hormones in formalin-induced pain responses of male rats: modulation by estradiol and naloxone administration. Neuroscience 95, 559-566. doi: 10.1016/S0306-4522(99)00445-5

Anda, R. F., Felitti, V. J., Bremner, J. D., Walker, J. D., Whitfield, C., Perry, B. D., et al. (2006). The enduring effects of abuse and related adverse experiences in childhood. A convergence of evidence from neurobiology and epidemiology. Eur. Arch. Psychiatry Clin. Neurosci. 256, 174-186. doi: 10.1007/s00406-005-0624-4

Annaházi, A., Dabek, M., Gecse, K., Salvador-Cartier, C., Polizzi, A., Rosztoczy, A., et al. (2012). Proteinase-activated receptor-4 evoked colorectal analgesia in mice: an endogenously activated feed-back loop in visceral inflammatory pain. Neurogastroenterol. Motil. 24, 76-85, e13. doi: 10.1111/j.1365-2982.2011.01805.x

Arroyo-Novoa, C. M., Figueroa-Ramos, M. I., Miaskowski, C., Padilla, G., Stotts, N., and Puntillo, K. A. (2009). Acute wound pain: gaining a better understanding. Adv. Skin Wound Care 22, 373-380; quiz 381-372. doi: 10.1097/01.ASW.0000358637.38161.8f

Asan, E., Steinke, M., and Lesch, K. P. (2013). Serotonergic innervation of the amygdala: targets, receptors, and implications for stress and anxiety. Histochem. Cell Biol. 139, 785-813. doi: 10.1007/s00418-013-1081-1

Avishai-Eliner, S., Gilles, E. E., Eghbal-Ahmadi, M., Bar-El, Y., and Baram, T. Z. (2001). Altered regulation of gene and protein expression of hypothalamic-pituitary-adrenal axis components in an immature rat model of chronic stress. J. Neuroendocrinol. 13, 799-807. doi: 10.1046/j.1365-2826.2001. 00698.x
Barbara, G., Feinle-Bisset, C., Ghoshal, U. C., Quigley, E. M., Santos, J., Vanner, S., et al. (2016). The intestinal microenvironment and functional gastrointestinal disorders. Gastroenterology 150, 1305-1318. doi: 10.1053/j.gastro.2016.02.028

Bashashati, M., Fichna, J., Piscitelli, F., Capasso, R., Izzo, A. A., Sibaev, A., et al. (2017). Targeting fatty acid amide hydrolase and transient receptor potential vanilloid-1 simultaneously to modulate colonic motility and visceral sensation in the mouse: a pharmacological intervention with $\mathrm{N}$-arachidonoylserotonin (AA-5-HT). Neurogastroenterol. Motil. doi: 10.1111/nmo. 13148. [Epub ahead of print].

Beggs, S., Currie, G., Salter, M. W., Fitzgerald, M., and Walker, S. M. (2012). Priming of adult pain responses by neonatal pain experience: maintenance by central neuroimmune activity. Brain 135, 404-417. doi: 10.1093/brain/awr288

Bernstein, B. E., Meissner, A., and Lander, E. S. (2007). The mammalian epigenome. Cell 128, 669-681. doi: 10.1016/j.cell.2007.01.033

Botschuijver, S., Roeselers, G., Levin, E., Jonkers, D. M., Welting, O., Heinsbroek, S. E. M., et al. (2017). Intestinal fungal dysbiosis associates with visceral hypersensitivity in patients with irritable bowel syndrome and rats. Gastroenterology 153, 1026-1039. doi: 10.1053/j.gastro.2017.06.004

Bowery, N. G., Bettler, B., Froestl, W., Gallagher, J. P., Marshall, F., Raiteri, M., et al. (2002). International Union of Pharmacology. XXXIII. Mammalian gammaaminobutyric acid(B) receptors: structure and function. Pharmacol. Rev. 54, 247-264.

Bradesi, S., Eutamene, H., Garcia-Villar, R., Fioramonti, J., and Bueno, L. (2002). Acute and chronic stress differently affect visceral sensitivity to rectal distension in female rats. Neurogastroenterol. Motil. 14, 75-82. doi: 10.1046/j.1365-2982.2002.00305.x

Bradesi, S., Karagiannides, I., Bakirtzi, K., Joshi, S. M., Koukos, G., Iliopoulos, D., et al. (2015). Identification of spinal cord MicroRNA and gene signatures in a model of chronic stress-induced visceral hyperalgesia in rat. PLOS ONE 10:e0130938. doi: 10.1371/journal.pone.0130938

Bradesi, S., Kokkotou, E., Simeonidis, S., Patierno, S., Ennes, H. S., Mittal, Y., et al. (2006). The role of neurokinin 1 receptors in the maintenance of visceral hyperalgesia induced by repeated stress in rats. Gastroenterology 130, 1729-1742. doi: 10.1053/j.gastro.2006.01.037

Bradesi, S., Lao, L., McLean, P. G., Winchester, W. J., Lee, K., Hicks, G. A., et al. (2007). Dual role of 5-HT3 receptors in a rat model of delayed stress-induced visceral hyperalgesia. Pain 130, 56-65. doi: 10.1016/j.pain.2006.10.028

Bradesi, S., Martinez, V., Lao, L., Larsson, H., and Mayer, E. A. (2009). Involvement of vasopressin 3 receptors in chronic psychological stress-induced visceral hyperalgesia in rats. Am. J. Physiol. Gastrointest. Liver Physiol. 296, G302-G309. doi: 10.1152/ajpgi.90557.2008

Bradesi, S., Schwetz, I., Ennes, H. S., Lamy, C. M., Ohning, G., Fanselow, M., et al. (2005). Repeated exposure to water avoidance stress in rats: a new model for sustained visceral hyperalgesia. Am. J. Physiol. Gastrointest. Liver Physiol. 289, G42-G53. doi: 10.1152/ajpgi.00500.2004

Bradford, K., Shih, W., Videlock, E. J., Presson, A. P., Naliboff, B. D. Mayer, E. A., et al. (2012). Association between early adverse life events and irritable bowel syndrome. Clin. Gastroenterol. Hepatol. 10, 385-390.e3. doi: 10.1016/j.cgh.2011.12.018

Braz, J., Solorzano, C., Wang, X., and Basbaum, A. I. (2014). Transmitting pain and itch messages: a contemporary view of the spinal cord circuits that generate gate control. Neuron 82, 522-536. doi: 10.1016/j.neuron.2014.01.018

Broers, C., Melchior, C., Van Oudenhove, L., Vanuytsel, T., Van Houtte, B., Scheerens, C., et al. (2017). The effect of intravenous corticotropinreleasing hormone administration on esophageal sensitivity and motility in health. Am. J. Physiol. Gastrointest. Liver Physiol. 312, G526-G534. doi: 10.1152/ajpgi.00437.2016

Brookes, S. J., Spencer, N. J., Costa, M., and Zagorodnyuk, V. P. (2013). Extrinsic primary afferent signalling in the gut. Nat. Rev. Gastroenterol. Hepatol. 10, 286-296. doi: 10.1038/nrgastro.2013.29

Bushnell, M. C., Ceko, M., and Low, L. A. (2013). Cognitive and emotional control of pain and its disruption in chronic pain. Nat. Rev. Neurosci. 14, 502-511. doi: $10.1038 / \mathrm{nrn} 3516$

Butler, R. K., and Finn, D. P. (2009). Stress-induced analgesia. Prog. Neurobiol. 88 , 184-202. doi: 10.1016/j.pneurobio.2009.04.003

Camilleri, M., Madsen, K., Spiller, R., Greenwood-Van Meerveld, B., and Verne, G. N. (2012). Intestinal barrier function in health and gastrointestinal disease. Neurogastroenterol. Motil. 24, 503-512. doi: 10.1111/j.1365-2982.2012.01921.x 
Camp, L. L., and Rudy, J. W. (1988). Changes in the categorization of appetitive and aversive events during postnatal development of the rat. Dev. Psychobiol. 21, 25-42. doi: 10.1002/dev.420210103

Cao, D. Y., Bai, G., Ji, Y., and Traub, R. J. (2015). Epigenetic upregulation of metabotropic glutamate receptor 2 in the spinal cord attenuates oestrogen-induced visceral hypersensitivity. Gut 64, 1913-1920. doi: 10.1136/gutjnl-2014-307748

Cao, D. Y., Bai, G., Ji, Y., Karpowicz, J. M., and Traub, R. J. (2016). EXPRESS: histone hyperacetylation modulates spinal type II metabotropic glutamate receptor alleviating stress-induced visceral hypersensitivity in female rats. Mol. Pain 12:1744806916660722. doi: 10.1177/1744806916660722

Castro, J., Harrington, A. M., Garcia-Caraballo, S., Maddern, J., Grundy, L., Zhang, J., et al. (2017). Alpha-Conotoxin Vc1.1 inhibits human dorsal root ganglion neuroexcitability and mouse colonic nociception via GABAB receptors. Gut 66, 1083-1094. doi: 10.1136/gutjnl-2015-310971

Chaloner, A., and Greenwood-Van Meerveld, B. (2013). Sexually dimorphic effects of unpredictable early life adversity on visceral pain behavior in a rodent model. J. Pain 14, 270-280. doi: 10.1016/j.jpain.2012.11.008

Chang, L., Toner, B. B., Fukudo, S., Guthrie, E., Locke, G. R., Norton, N. J., et al. (2006). Gender, age, society, culture, and the patient's perspective in the functional gastrointestinal disorders. Gastroenterology 130, 1435-1446. doi: 10.1053/j.gastro.2005.09.071

Chen, J. H., Wei, S. Z., Chen, J., Wang, Q., Liu, H. L., Gao, X. H., et al. (2009). Sensory denervation reduces visceral hypersensitivity in adult rats exposed to chronic unpredictable stress: evidences of neurogenic inflammation. Dig. Dis. Sci. 54, 1884-1891. doi: 10.1007/s10620-008-0575-5

Chen, J., Winston, J. H., and Sarna, S. K. (2013). Neurological and cellular regulation of visceral hypersensitivity induced by chronic stress and colonic inflammation in rats. Neuroscience 248C, 469-478. doi: 10.1016/j.neuroscience.2013.06.024

Chial, H. J., and Camilleri, M. (2002). Gender differences in irritable bowel syndrome. J. Gend. Specif. Med. 5, 37-45.

Coutinho, S. V., Plotsky, P. M., Sablad, M., Miller, J. C., Zhou, H., Bayati, A. I., et al. (2002). Neonatal maternal separation alters stress-induced responses to viscerosomatic nociceptive stimuli in rat. Am. J. Physiol. Gastrointest. Liver Physiol. 282, G307-G316. doi: 10.1152/aipgi.00240.2001

da Costa Gomez, T. M., and Behbehani, M. M. (1995). An electrophysiological characterization of the projection from the central nucleus of the amygdala to the periaqueductal gray of the rat: the role of opioid receptors. Brain Res. 689, 21-31. doi: 10.1016/0006-8993(95)00525-U

Da Silva, S., Robbe-Masselot, C., Ait-Belgnaoui, A., Mancuso, A., MercadeLoubiere, M., Salvador-Cartier, C., et al. (2014). Stress disrupts intestinal mucus barrier in rats via mucin O-glycosylation shift: prevention by a probiotic treatment. Am. J. Physiol. Gastrointest. Liver Physiol. 307, G420-G429. doi: 10.1152/ajpgi.00290.2013

Darbaky, Y., Evrard, B., Patrier, S., Falenta, J., Garcin, S., Tridon, A., et al. (2017). Oral probiotic treatment of Lactobacillus rhamnosus Lcr35(R) prevents visceral hypersensitivity to a colonic inflammation and an acute psychological stress. J. Appl. Microbiol. 122, 188-200. doi: 10.1111/jam.13320

de Kloet, E. R., Joels, M., and Holsboer, F. (2005). Stress and the brain: from adaptation to disease. Nat. Rev. Neurosci. 6, 463-475. doi: 10.1038/nrn1683

Denk, F., Mcmahon, S. B., and Tracey, I. (2014). Pain vulnerability: a neurobiological perspective. Nat. Neurosci. 17, 192-200. doi: 10.1038/nn.3628

Dhabhar, F. S., Mcewen, B. S., and Spencer, R. L. (1997). Adaptation to prolonged or repeated stress-comparison between rat strains showing intrinsic differences in reactivity to acute stress. Neuroendocrinology 65, 360-368.

Di, S., Malcher-Lopes, R., Halmos, K. C., and Tasker, J. G. (2003). Nongenomic glucocorticoid inhibition via endocannabinoid release in the hypothalamus: a fast feedback mechanism. J. Neurosci. 23, 4850-4857.

Dina, O. A., Khasar, S. G., Alessandri-Haber, N., Green, P. G., Messing, R. O., and Levine, J. D. (2008). Alcohol-induced stress in painful alcoholic neuropathy. Eur. J. Neurosci. 27, 83-92. doi: 10.1111/j.1460-9568.2007.05987.x

Dong, F., Xie, W., Strong, J. A., and Zhang, J. M. (2012). Mineralocorticoid receptor blocker eplerenone reduces pain behaviors in vivo and decreases excitability in small-diameter sensory neurons from local inflamed dorsal root ganglia in vitro. Anesthesiology 117, 1102-1112. doi: 10.1097/ALN.0b013e3182700383

Drake, B., and Pandey, S. (1996). Understanding the relationship between neighborhood poverty and specific types of child maltreatment. Child Abuse Negl. 20, 1003-1018. doi: 10.1016/0145-2134(96)00091-9
Drossman, D. A., Chang, L., Bellamy, N., Gallo-Torres, H. E., Lembo, A., Mearin, F., et al. (2011). Severity in irritable bowel syndrome: a Rome foundation working team report. Am. J. Gastroenterol. 106, 1749-1759; quiz 1760. doi: 10.1038/ajg.2011.201

Drossman, D. A., Leserman, J., Nachman, G., Li, Z. M., Gluck, H., Toomey, T. C., et al. (1990). Sexual and physical abuse in women with functional or organic gastrointestinal disorders. Ann. Intern. Med. 113, 828-833. doi: 10.7326/0003-4819-113-11-828

Eckersell, C. B., Popper, P., and Micevych, P. E. (1998). Estrogen-induced alteration of mu-opioid receptor immunoreactivity in the medial preoptic nucleus and medial amygdala. J. Neurosci. 18, 3967-3976.

Enna, S. J., and Bowery, N. G. (2004). GABA(B) receptor alterations as indicators of physiological and pharmacological function. Biochem. Pharmacol. 68, 1541-1548. doi: 10.1016/j.bcp.2004.06.037

Eutamene, H., Bradesi, S., Larauche, M., Theodorou, V., Beaufrand, C., Ohning, G., et al. (2010). Guanylate cyclase C-mediated antinociceptive effects of linaclotide in rodent models of visceral pain. Neurogastroenterol. Motil. 22, 312-e384. doi: 10.1111/j.1365-2982.2009.01385.x

Evanson, N. K., Tasker, J. G., Hill, M. N., Hillard, C. J., and Herman, J. P. (2010). Fast feedback inhibition of the HPA axis by glucocorticoids is mediated by endocannabinoid signaling. Endocrinology 151, 4811-4819. doi: 10.1210/en.2010-0285

Farh, K. K., Grimson, A., Jan, C., Lewis, B. P., Johnston, W. K., Lim, L. P., et al. (2005). The widespread impact of mammalian MicroRNAs on mRNA repression and evolution. Science 310, 1817-1821. doi: 10.1126/science.1121158

Fichna, J., Salaga, M., Stuart, J., Saur, D., Sobczak, M., Zatorski, H., et al. (2014). Selective inhibition of FAAH produces antidiarrheal and antinociceptive effect mediated by endocannabinoids and cannabinoid-like fatty acid amides. Neurogastroenterol. Motil. 26, 470-481. doi: 10.1111/nmo.12272

Fichna, J., Wood, J. T., Papanastasiou, M., Vadivel, S. K., Oprocha, P., Salaga, M., et al. (2013). Endocannabinoid and cannabinoid-like fatty acid amide levels correlate with pain-related symptoms in patients with IBS-D and IBS-C: a pilot study. PLoS ONE 8:e85073. doi: 10.1371/journal.pone.0085073

Fioramonti, J., Gaultier, E., Toulouse, M., Sanger, G. J., and Bueno, L. (2003). Intestinal anti-nociceptive behaviour of NK3 receptor antagonism in conscious rats: evidence to support a peripheral mechanism of action. Neurogastroenterol. Motil. 15, 363-369. doi: 10.1046/j.1365-2982.2003.00420.x

Fitch, R. H., and Denenberg, V. H. (1998). A role for ovarian hormones in sexual differentiation of the brain. Behav. Brain Sci. 21, 311-327; discussion 327-352.

Fornasari, D. (2012). Pain mechanisms in patients with chronic pain. Clin. Drug Investig. 32(Suppl. 1), 45-52. doi: 10.2165/11630070-000000000-00000

Fourie, N. H., Peace, R. M., Abey, S. K., Sherwin, L. B., Rahim-Williams, B., Smyser, P. A., et al. (2014). Elevated circulating miR-150 and miR-342-3p in patients with irritable bowel syndrome. Exp. Mol. Pathol. 96, 422-425. doi: 10.1016/j.yexmp.2014.04.009

Gallagher, J. P., Orozco-Cabal, L. F., Liu, J., and Shinnick-Gallagher, P. (2008). Synaptic physiology of central CRH system. Eur. J. Pharmacol. 583, 215-225. doi: 10.1016/j.ejphar.2007.11.075

Gilet, M., Eutamene, H., Han, H., Kim, H. W., and Bueno, L. (2014). Influence of a new 5-HT4 receptor partial agonist, YKP10811, on visceral hypersensitivity in rats triggered by stress and inflammation. Neurogastroenterol. Motil. 26, 1761-1770. doi: 10.1111/nmo. 12458

Gilles, E. E., Schultz, L., and Baram, T. Z. (1996). Abnormal corticosterone regulation in an immature rat model of continuous chronic stress. Pediatr. Neurol. 15, 114-119. doi: 10.1016/0887-8994(96)00153-1

Gillespie, C. F., Phifer, J., Bradley, B., and Ressler, K. J. (2009). Risk and resilience: genetic and environmental influences on development of the stress response. Depress. Anxiety 26, 984-992. doi: 10.1002/da.20605

Girotti, M., Pace, T. W., Gaylord, R. I., Rubin, B. A., Herman, J. P., and Spencer, R. L. (2006). Habituation to repeated restraint stress is associated with lack of stress-induced c-fos expression in primary sensory processing areas of the rat brain. Neuroscience 138, 1067-1081. doi: 10.1016/j.neuroscience.2005. 12.002

Gorzalka, B. B., Hill, M. N., and Hillard, C. J. (2008). Regulation of endocannabinoid signaling by stress: implications for stressrelated affective disorders. Neurosci. Biobehav. Rev. 32, 1152-1160. doi: 10.1016/j.neubiorev.2008.03.004

Goudet, C., Magnaghi, V., Landry, M., Nagy, F., Gereau, R. W. T., and Pin, J. P. (2009). Metabotropic receptors for glutamate and GABA in pain. Brain Res. Rev. 60, 43-56. doi: 10.1016/j.brainresrev.2008.12.007 
Grace, P. M., Hutchinson, M. R., Maier, S. F., and Watkins, L. R. (2014). Pathological pain and the neuroimmune interface. Nat. Rev. Immunol. 14, 217-231. doi: 10.1038/nri3621

Greenwood-Van Meerveld, B., Gibson, M., Gunter, W., Shepard, J., Foreman, R., and Myers, D. (2001). Stereotaxic delivery of corticosterone to the amygdala modulates colonic sensitivity in rats. Brain Res. 893, 135-142. doi: 10.1016/S0006-8993(00)03305-9

Greenwood-Van Meerveld, B., Prusator, D. K., and Johnson, A. C. (2015). Animal models of gastrointestinal and liver diseases. Animal models of visceral pain: pathophysiology, translational relevance, and challenges. Am. J. Physiol. Gastrointest. Liver Physiol. 308, G885-G903. doi: 10.1152/ajpgi.00463.2014

Greenwood-Van Meerveld, B., Prusator, D. K., Ligon, C. O., Johnson, A. C., and Moloney, R. D. (2016). "Chapter 41 - Epigenetics of Pain Management A2," in Medical Epigenetics, ed T.O. Tollefsbol (Boston, MA: Academic Press), 827-841. doi: 10.1016/B978-0-12-803239-8.00041-7

Griebel, G., Pichat, P., Beeske, S., Leroy, T., Redon, N., Jacquet, A., et al. (2015). Selective blockade of the hydrolysis of the endocannabinoid 2-arachidonoylglycerol impairs learning and memory performance while producing antinociceptive activity in rodents. Sci. Rep. 5:7642. doi: 10.1038/srep07642

Gu, X., Wang, S., Yang, L., Sung, B., Lim, G., Mao, J., et al. (2007). Timedependent effect of epidural steroid on pain behavior induced by chronic compression of dorsal root ganglion in rats. Brain Res. 1174, 39-46. doi: 10.1016/j.brainres.2007.08.030

Gué, M., Del Rio-Lacheze, C., Eutamene, H., Theodorou, V., Fioramonti, J., and Bueno, L. (1997). Stress-induced visceral hypersensitivity to rectal distension in rats: role of CRF and mast cells. Neurogastroenterol. Motil. 9, 271-279. doi: 10.1046/j.1365-2982.1997.d01-63.x

Gunn, B. G., Cunningham, L., Mitchell, S., Swinny, J. D., Lambert, J. J., and Belelli, D. (2014). GABA receptor-acting neurosteroids: a role in the development and regulation of the stress response. Front. Neuroendocrinol. 36, 28-48. doi: 10.1016/j.yfrne.2014.06.001

Gupta, A., Kilpatrick, L., Labus, J., Tillisch, K., Braun, A., Hong, J. Y., et al. (2014). Early adverse life events and resting state neural networks in patients with chronic abdominal pain: evidence for sex differences. Psychosom. Med. 76, 404-412. doi: 10.1097/PSY.0000000000000089

Gustafsson, J. K., and Greenwood-Van Meerveld, B. (2011). Amygdala activation by corticosterone alters visceral and somatic pain in cycling female rats. Am. J. Physiol. Gastrointest. Liver Physiol. 300, G1080-G1085. doi: 10.1152/ajpgi.00349.2010

Haller, J., Mikics, E., and Makara, G. B. (2008). The effects of non-genomic glucocorticoid mechanisms on bodily functions and the central neural system. A critical evaluation of findings. Front. Neuroendocrinol. 29, 273-291. doi: 10.1016/j.yfrne.2007.10.004

Hammes, S. R., and Levin, E. R. (2011). Minireview: recent advances in extranuclear steroid receptor actions. Endocrinology 152, 4489-4495. doi: 10.1210/en.2011-1470

Handa, R. J., Burgess, L. H., Kerr, J. E., and O’keefe, J. A. (1994). Gonadal steroid hormone receptors and sex differences in the hypothalamo-pituitary-adrenal axis. Horm. Behav. 28, 464-476. doi: 10.1006/hbeh.1994.1044

Heinricher, M. M., Tavares, I., Leith, J. L., and Lumb, B. M. (2009). Descending control of nociception: specificity, recruitment and plasticity. Brain Res. Rev. 60, 214-225. doi: 10.1016/j.brainresrev.2008.12.009

Heitkemper, M. M., and Chang, L. (2009). Do fluctuations in ovarian hormones affect gastrointestinal symptoms in women with irritable bowel syndrome? Gend. Med. 6(Suppl. 2), 152-167. doi: 10.1016/j.genm.2009.03.004

Heitkemper, M., and Jarrett, M. (2008). Irritable bowel syndrome: does gender matter? J. Psychosom. Res. 64, 583-587. doi: 10.1016/j.jpsychores.2008.02.020

Herman, J. P., and Cullinan, W. E. (1997). Neurocircuitry of stress: central control of the hypothalamo-pituitary-adrenocortical axis. Trends Neurosci. 20, 78-84. doi: 10.1016/S0166-2236(96)10069-2

Hill, M. N., and McEwen, B. S. (2010). Involvement of the endocannabinoid system in the neurobehavioural effects of stress and glucocorticoids. Prog. Neuropsychopharmacol. Biol. Psychiatry 34, 791-797. doi: 10.1016/j.pnpbp.2009.11.001

Hillhouse, T. M., and Negus, S. S. (2016). Effects of the noncompetitive Nmethyl-d-aspartate receptor antagonists ketamine and MK-801 on painstimulated and pain-depressed behaviour in rats. Eur. J. Pain 20, 1229-1240. doi: 10.1002/ejp.847
Holschneider, D. P., Guo, Y., Mayer, E. A., and Wang, Z. (2016). Early life stress elicits visceral hyperalgesia and functional reorganization of pain circuits in adult rats. Neurobiol. Stress 3, 8-22. doi: 10.1016/j.ynstr.2015.12.003

Hong, S., Fan, J., Kemmerer, E. S., Evans, S., Li, Y., and Wiley, J. W. (2009). Reciprocal changes in vanilloid (TRPV1) and endocannabinoid (CB1) receptors contribute to visceral hyperalgesia in the water avoidance stressed rat. Gut 58, 202-210. doi: 10.1136/gut.2008.157594

Hong, S., Zheng, G., and Wiley, J. W. (2015). Epigenetic regulation of genes that modulate chronic stress-induced visceral pain in the peripheral nervous system. Gastroenterology 148, 148-157.e7. doi: 10.1053/j.gastro.2014.09.032

Hong, S., Zheng, G., Wu, X., Snider, N. T., Owyang, C., and Wiley, J. W. (2011). Corticosterone mediates reciprocal changes in CB 1 and TRPV1 receptors in primary sensory neurons in the chronically stressed rat. Gastroenterology 140, 148-157.e7. doi: 10.1053/j.gastro.2010.11.003

Hooten, W. M. (2016). Chronic pain and mental health disorders: shared neural mechanisms, epidemiology, and treatment. Mayo Clin. Proc. 91, 955-970. doi: 10.1016/j.mayocp.2016.04.029

Icenhour, A., Witt, S. T., Elsenbruch, S., Lowen, M., Engstrom, M., Tillisch, K., et al. (2017). Brain functional connectivity is associated with visceral sensitivity in women with Irritable Bowel Syndrome. Neuroimage Clin. 15, 449-457. doi: 10.1016/j.nicl.2017.06.001

Ivy, A. S., Brunson, K. L., Sandman, C., and Baram, T. Z. (2008). Dysfunctional nurturing behavior in rat dams with limited access to nesting material: a clinically relevant model for early-life stress. Neuroscience 154, 1132-1142. doi: 10.1016/j.neuroscience.2008.04.019

Jaggi, A. S., and Singh, N. (2011). Role of different brain areas in peripheral nerve injury-induced neuropathic pain. Brain Res. 1381, 187-201. doi: 10.1016/j.brainres.2011.01.002

Ji, G., and Neugebauer, V. (2007). Differential effects of CRF1 and CRF2 receptor antagonists on pain-related sensitization of neurons in the central nucleus of the amygdala. J. Neurophysiol. 97, 3893-3904. doi: 10.1152/jn.00135.2007

Ji, G., and Neugebauer, V. (2008). Pro- and anti-nociceptive effects of corticotropin-releasing factor (CRF) in central amygdala neurons are mediated through different receptors. J. Neurophysiol. 99, 1201-1212. doi: 10.1152/jn.01148.2007

Ji, Y., Bai, G., Cao, D. Y., and Traub, R. J. (2015). Estradiol modulates visceral hyperalgesia by increasing thoracolumbar spinal GluN2B subunit activity in female rats. Neurogastroenterol. Motil. 27, 775-786. doi: 10.1111/nmo.12549

Ji, Y., Tang, B., and Traub, R. J. (2008). The visceromotor response to colorectal distention fluctuates with the estrous cycle in rats. Neuroscience 154, 1562-1567. doi: 10.1016/j.neuroscience.2008.04.070

Jia, F. Y., Li, X. L., Li, T. N., Wu, J., Xie, B. Y., and Lin, L. (2013). Role of nesfatin-1 in a rat model of visceral hypersensitivity. World J. Gastroenterol. 19, 3487-3493. doi: 10.3748/wjg.v19.i22.3487

Johnson, A. C., and Greenwood Van-Meerveld, B. (2012). Evidence to support the non-genomic modulation of the HPA axis. J. Steroids Horm. Sci. 3:e109. doi: 10.4172/2157-7536.1000e109

Johnson, A. C., and Greenwood-Van Meerveld, B. (2015). Knockdown of steroid receptors in the central nucleus of the amygdala induces heightened pain behaviors in the rat. Neuropharmacology 93, 116-123. doi: 10.1016/j.neuropharm.2015.01.018

Johnson, A. C., and Greenwood-Van Meerveld, B. (2017). Critical evaluation of animal models of gastrointestinal disorders. Handb. Exp. Pharmacol. 239, 289-317. doi: 10.1007/164_2016_120

Johnson, A. C., Myers, B., Lazovic, J., Towner, R., and Greenwood-Van Meerveld, B. (2010). Brain activation in response to visceral stimulation in rats with amygdala implants of corticosterone: an FMRI study. PLoS ONE 5:e8573. doi: 10.1371/journal.pone.0008573

Johnson, A. C., Tran, L., and Greenwood-Van Meerveld, B. (2015). Knockdown of corticotropin-releasing factor in the central amygdala reverses persistent viscerosomatic hyperalgesia. Transl. Psychiatry 5:e517. doi: 10.1038/tp.2015.16

Johnson, A. C., Tran, L., Schulkin, J., and Greenwood-Van Meerveld, B. (2012). Importance of stress receptor-mediated mechanisms in the amygdala on visceral pain perception in an intrinsically anxious rat. Neurogastroenterol. Motil. 24, 479-486. doi: 10.1111/j.1365-2982.2012.01899.x

Johnson, L. R., Farb, C., Morrison, J. H., Mcewen, B. S., and Ledoux, J. E. (2005). Localization of glucocorticoid receptors at postsynaptic membranes in the lateral amygdala. Neuroscience 136, 289-299. doi: 10.1016/j.neuroscience.2005.06.050 
Johnson, M. P., Muhlhauser, M. A., Nisenbaum, E. S., Simmons, R. M., Forster, B. M., Knopp, K. L., et al. (2017). Broad spectrum efficacy with LY2969822, an oral prodrug of metabotropic glutamate $2 / 3$ receptor agonist LY2934747, in rodent pain models. Br. J. Pharmacol. 174, 822-835. doi: 10.1111/bph.13740

Kalinichev, M., Girard, F., Haddouk, H., Rouillier, M., Riguet, E., Royer-Urios, I., et al. (2017). The drug candidate, ADX71441, is a novel, potent and selective positive allosteric modulator of the GABAB receptor with a potential for treatment of anxiety, pain and spasticity. Neuropharmacology 114, 34-47. doi: 10.1016/j.neuropharm.2016.11.016

Kane, S. V., Sable, K., and Hanauer, S. B. (1998). The menstrual cycle and its effect on inflammatory bowel disease and irritable bowel syndrome: a prevalence study. Am. J. Gastroenterol. 93, 1867-1872. doi: 10.1111/j.1572-0241.1998.540_i.x

Kannampalli, P., Babygirija, R., Zhang, J., Poe, M. M., Li, G., Cook, J. M., et al. (2017a). Neonatal bladder inflammation induces long-term visceral pain and altered responses of spinal neurons in adult rats. Neuroscience 346, 349-364. doi: 10.1016/j.neuroscience.2017.01.021

Kannampalli, P., Poli, S. M., Bolea, C., and Sengupta, J. N. (2017b). Analgesic effect of ADX71441, a positive allosteric modulator (PAM) of GABAB receptor in a rat model of bladder pain. Neuropharmacology 126, 1-11. doi: 10.1016/j.neuropharm.2017.08.023

Karst, H., Berger, S., Turiault, M., Tronche, F., Schutz, G., and Joels, M. (2005). Mineralocorticoid receptors are indispensable for nongenomic modulation of hippocampal glutamate transmission by corticosterone. Proc. Natl. Acad. Sci. U.S.A. 102, 19204-19207. doi: 10.1073/pnas.0507572102

Kayser, V., Berkley, K. J., Keita, H., Gautron, M., and Guilbaud, G. (1996). Estrous and sex variations in vocalization thresholds to hindpaw and tail pressure stimulation in the rat. Brain Res. 742, 352-354. doi: 10.1016/S0006-8993(96)01108-0

Kuner, R. (2010). Central mechanisms of pathological pain. Nat. Med. 16, 1258-1266. doi: 10.1038/nm.2231

Laessle, R. G., Tuschl, R. J., Schweiger, U., and Pirke, K. M. (1990). Mood changes and physical complaints during the normal menstrual cycle in healthy young women. Psychoneuroendocrinology 15, 131-138.

Lampe, A., Doering, S., Rumpold, G., Solder, E., Krismer, M., KantnerRumplmair, W., et al. (2003). Chronic pain syndromes and their relation to childhood abuse and stressful life events. J. Psychosom. Res. 54, 361-367. doi: 10.1016/S0022-3999(02)00399-9

Larauche, M., Gourcerol, G., Wang, L., Pambukchian, K., Brunnhuber, S., Adelson, D. W., et al. (2009). Cortagine, a CRF1 agonist, induces stresslike alterations of colonic function and visceral hypersensitivity in rodents primarily through peripheral pathways. Am. J. Physiol. Gastrointest. Liver Physiol. 297, G215-G227. doi: 10.1152/ajpgi.00072.2009

Lee, U. J., Ackerman, A. L., Wu, A., Zhang, R., Leung, J., Bradesi, S., et al. (2015). Chronic psychological stress in high-anxiety rats induces sustained bladder hyperalgesia. Physiol. Behav. 139, 541-548. doi: 10.1016/j.physbeh.2014. 11.045

Leyro, T. M., Zvolensky, M. J., and Bernstein, A. (2010). Distress tolerance and psychopathological symptoms and disorders: a review of the empirical literature among adults. Psychol. Bull. 136, 576-600. doi: 10.1037/a0019712

Liao, X. J., Mao, W. M., Wang, Q., Yang, G. G., Wu, W. J., and Shao, S. X. (2016). MicroRNA-24 inhibits serotonin reuptake transporter expression and aggravates irritable bowel syndrome. Biochem. Biophys. Res. Commun. 469, 288-293. doi: 10.1016/j.bbrc.2015.11.102

Ligon, C. O., Moloney, R. D., and Greenwood-Van Meerveld, B. (2016). Targeting epigenetic mechanisms for chronic pain: a valid approach for the development of novel therapeutics. J. Pharmacol. Exp. Ther. 357, 84-93. doi: 10.1124/jpet.115.231670

Liu, H. R., Fang, X. Y., Wu, H. G., Wu, L. Y., Li, J., Weng, Z. J., et al. (2015). Effects of electroacupuncture on corticotropin-releasing hormone in rats with chronic visceral hypersensitivity. World J. Gastroenterol. 21, 7181-7190. doi: 10.3748/wjg.v21.i23.7181

Liu, S. B., Zhang, M. M., Cheng, L. F., Shi, J., Lu, J. S., and Zhuo, M. (2015). Longterm upregulation of cortical glutamatergic AMPA receptors in a mouse model of chronic visceral pain. Mol. Brain 8:76. doi: 10.1186/s13041-015-0169-z

Liu, S., Hagiwara, S. I., and Bhargava, A. (2017). Early-life adversity, epigenetics, and visceral hypersensitivity. Neurogastroenterol. Motil. 29:e13170. doi: $10.1111 / \mathrm{nmo} .13170$
Lu, N. Z., Wardell, S. E., Burnstein, K. L., Defranco, D., Fuller, P. J., Giguere, V., et al. (2006). International Union of Pharmacology. LXV. The pharmacology and classification of the nuclear receptor superfamily: glucocorticoid, mineralocorticoid, progesterone, and androgen receptors. Pharmacol. Rev. 58, 782-797. doi: 10.1124/pr.58.4.9

Luongo, L., Maione, S., and Di Marzo, V. (2014). Endocannabinoids and neuropathic pain: focus on neuron-glia and endocannabinoidneurotrophin interactions. Eur. J. Neurosci. 39, 401-408. doi: 10.1111/ejn. 12440

Ly, H. G., Ceccarini, J., Weltens, N., Bormans, G., Van Laere, K., Tack, J., et al. (2015). Increased cerebral cannabinoid-1 receptor availability is a stable feature of functional dyspepsia: a [F]MK-9470 PET study. Psychother. Psychosom. 84, 149-158. doi: 10.1159/000375454

Ma, X., Li, S., Tian, J., Jiang, G., Wen, H., Wang, T., et al. (2015). Altered brain spontaneous activity and connectivity network in irritable bowel syndrome patients: a resting-state fMRI study. Clin. Neurophysiol. 126, 1190-1197. doi: 10.1016/j.clinph.2014.10.004

Maizels, M., Aurora, S., and Heinricher, M. (2012). Beyond neurovascular: migraine as a dysfunctional neurolimbic pain network. Headache 52, 1553-1565. doi: 10.1111/j.1526-4610.2012.02209.x

Matos, R., Serrao, P., Rodriguez, L., Birder, L. A., Cruz, F., and Charrua, A. (2017). The water avoidance stress induces bladder pain due to a prolonged alpha1A adrenoceptor stimulation. Naunyn Schmiedebergs. Arch. Pharmacol. 390, 839-844. doi: 10.1007/s00210-017-1384-1

McIlwrath, S. L., and Westlund, K. N. (2015). Pharmacological attenuation of chronic alcoholic pancreatitis induced hypersensitivity in rats. World J. Gastroenterol. 21, 836-853. doi: 10.3748/wjg.v21.i3.836

McLean, S. A., Williams, D. A., Stein, P. K., Harris, R. E., Lyden, A. K., Whalen, G., et al. (2006). Cerebrospinal fluid corticotropin-releasing factor concentration is associated with pain but not fatigue symptoms in patients with fibromyalgia. Neuropsychopharmacology 31, 2776-2782. doi: 10.1038/sj.npp. 1301200

Meleine, M., and Matricon, J. (2014). Gender-related differences in irritable bowel syndrome: potential mechanisms of sex hormones. World J. Gastroenterol. 20, 6725-6743. doi: 10.3748/wjg.v20.i22.6725

Miller, W. J., Suzuki, S., Miller, L. K., Handa, R., and Uht, R. M. (2004). Estrogen receptor (ER)beta isoforms rather than ERalpha regulate corticotropinreleasing hormone promoter activity through an alternate pathway. J. Neurosci. 24, 10628-10635. doi: 10.1523/JNEUROSCI.5540-03.2004

Million, M., Wang, L., Wang, Y., Adelson, D. W., Yuan, P. Q., Maillot, C., et al. (2006). CRF2 receptor activation prevents colorectal distension induced visceral pain and spinal ERK1/2 phosphorylation in rats. Gut 55, 172-181. doi: 10.1136/gut.2004.051391

Million, M., Zhao, J. F., Luckey, A., Czimmer, J., Maynard, G. D., Kehne, J., et al. (2013). The newly developed CRF1-receptor antagonists, NGD 98-2 and NGD 9002, suppress acute stress-induced stimulation of colonic motor function and visceral hypersensitivity in rats. PLoS ONE 8:e73749. doi: 10.1371/journal.pone.0073749

Miquel, S., Martin, R., Lashermes, A., Gillet, M., Meleine, M., Gelot, A., et al. (2016). Anti-nociceptive effect of Faecalibacterium prausnitzii in noninflammatory IBS-like models. Sci. Rep. 6:19399. doi: 10.1038/srep19399

Miranda, A., and Saps, M. (2014). The use of non-narcotic pain medication in pediatric gastroenterology. Paediatr. Drugs 16, 293-307. doi: 10.1007/s40272-014-0080-6

Mishra, S. P., Shukla, S. K., and Pandey, B. L. (2014). A preliminary evaluation of comparative effectiveness of riluzole in therapeutic regimen for irritable bowel syndrome. Asian Pac. J. Trop. Biomed. 4, S335-340. doi: 10.12980/APJTB.4.2014C205

Mitra, R., and Sapolsky, R. M. (2008). Acute corticosterone treatment is sufficient to induce anxiety and amygdaloid dendritic hypertrophy. Proc. Natl. Acad. Sci. U.S.A. 105, 5573-5578. doi: 10.1073/pnas.0705615105

Moloney, R. D., Stilling, R. M., Dinan, T. G., and Cryan, J. F. (2015). Earlylife stress-induced visceral hypersensitivity and anxiety behavior is reversed by histone deacetylase inhibition. Neurogastroenterol. Motil. 27, 1831-1836. doi: $10.1111 / \mathrm{nmo} .12675$

Mora, F., Segovia, G., Del Arco, A., De Blas, M., and Garrido, P. (2012). Stress, neurotransmitters, corticosterone and body-brain integration. Brain Res. 1476 71-85. doi: 10.1016/j.brainres.2011.12.049 
Moriceau, S., and Sullivan, R. M. (2004). Corticosterone influences on Mammalian neonatal sensitive-period learning. Behav. Neurosci. 118, 274-281. doi: 10.1037/0735-7044.118.2.274

Moriceau, S., Wilson, D. A., Levine, S., and Sullivan, R. M. (2006). Dual circuitry for odor-shock conditioning during infancy: corticosterone switches between fear and attraction via amygdala. J. Neurosci. 26, 6737-6748. doi: 10.1523/JNEUROSCI.0499-06.2006

Morton, D. L., Sandhu, J. S., and Jones, A. K. (2016). Brain imaging of pain: state of the art. J. Pain Res. 9, 613-624. doi: 10.2147/JPR.S60433

Mulak, A., Larauche, M., Biraud, M., Million, M., Rivier, J., and Tache, Y. (2015). Selective agonists of somatostatin receptor subtype 1 or 2 injected peripherally induce antihyperalgesic effect in two models of visceral hypersensitivity in mice. Peptides 63, 71-80. doi: 10.1016/j.peptides.2014.10.013

Munro, G., Hansen, R. R., and Mirza, N. R. (2013). GABA(A) receptor modulation: potential to deliver novel pain medicines? Eur. J. Pharmacol. 716, 17-23. doi: 10.1016/j.ejphar.2013.01.070

Myers, B., and Greenwood-Van Meerveld, B. (2007). Corticosteroid receptormediated mechanisms in the amygdala regulate anxiety and colonic sensitivity. Am. J. Physiol. Gastrointest. Liver Physiol. 292, G1622-G1629. doi: 10.1152/ajpgi.00080.2007

Myers, B., and Greenwood-Van Meerveld, B. (2010a). Divergent effects of amygdala glucocorticoid and mineralocorticoid receptors in the regulation of visceral and somatic pain. Am. J. Physiol. Gastrointest. Liver Physiol. 298, G295-G303. doi: 10.1152/ajpgi.00298.2009

Myers, B., and Greenwood-Van Meerveld, B. (2010b). Elevated corticosterone in the amygdala leads to persistent increases in anxiety-like behavior and pain sensitivity. Behav. Brain Res. 214, 465-469. doi: 10.1016/j.bbr.2010.05.049

Myers, B., and Greenwood-Van Meerveld, B. (2012). Differential involvement of amygdala corticosteroid receptors in visceral hyperalgesia following acute or repeated stress. Am. J. Physiol. Gastrointest. Liver Physiol. 302, G260-G266. doi: 10.1152/ajpgi.00353.2011

Myers, B., Dittmeyer, K., and Greenwood-Van Meerveld, B. (2007). Involvement of amygdaloid corticosterone in altered visceral and somatic sensation. Behav. Brain Res. 181, 163-167. doi: 10.1016/j.bbr.2007.03.031

Myers, B., Schulkin, J., and Greenwood-Van Meerveld, B. (2011). Sex steroids localized to the amygdala increase pain responses to visceral stimulation in rats. J. Pain 12, 486-494. doi: 10.1016/j.jpain.2010.10.007

Nakagawa, S., and Cuthill, I. C. (2007). Effect size, confidence interval and statistical significance: a practical guide for biologists. Biol. Rev. Camb. Philos. Soc. 82, 591-605. doi: 10.1111/j.1469-185X.2007.00027.x

Naliboff, B. D., Berman, S., Chang, L., Derbyshire, S. W., Suyenobu, B., Vogt, B. A., et al. (2003). Sex-related differences in IBS patients: central processing of visceral stimuli. Gastroenterology 124, 1738-1747. doi: 10.1016/S0016-5085(03)00400-1

Nash, M. S., Mcintyre, P., Groarke, A., Lilley, E., Culshaw, A., Hallett, A., et al. (2012). 7-tert-Butyl-6-(4-chloro-phenyl)-2-thioxo-2,3-dihydro-1Hpyrido[2,3-d]pyrimidin-4 -one, a classic polymodal inhibitor of transient receptor potential vanilloid type 1 with a reduced liability for hyperthermia, is analgesic and ameliorates visceral hypersensitivity. J. Pharmacol. Exp. Ther. 342, 389-398. doi: 10.1124/jpet.112.191932

Navratilova, E., and Porreca, F. (2014). Reward and motivation in pain and pain relief. Nat. Neurosci. 17, 1304-1312. doi: 10.1038/nn.3811

Navratilova, E., Xie, J. Y., King, T., and Porreca, F. (2013). Evaluation of reward from pain relief. Ann. N. Y. Acad. Sci. 1282, 1-11. doi: 10.1111/nyas. 12095

Nébot-Vivinus, M., Harkat, C., Bzioueche, H., Cartier, C., Plichon-Dainese, R., Moussa, L., et al. (2014). Multispecies probiotic protects gut barrier function in experimental models. World J. Gastroenterol. 20, 6832-6843. doi: 10.3748/wjg.v20.i22.6832

Nozu, T., Takakusaki, K., and Okumura, T. (2014). A balance theory of peripheral corticotropin-releasing factor receptor type 1 and type 2 signaling to induce colonic contractions and visceral hyperalgesia in rats. Endocrinology 155, 4655-4664. doi: 10.1210/en.2014-1421

Ochoa-Cortes, F., Guerrero-Alba, R., Valdez-Morales, E. E., Spreadbury, I., Barajas-Lopez, C., Castro, M., et al. (2014). Chronic stress mediators act synergistically on colonic nociceptive mouse dorsal root ganglia neurons to increase excitability. Neurogastroenterol. Motil. 26, 334-345. doi: $10.1111 /$ nmo. 12268
Ohashi-Doi, K., Himaki, D., Nagao, K., Kawai, M., Gale, J. D., Furness, J. B., et al. (2010). A selective, high affinity 5-HT 2B receptor antagonist inhibits visceral hypersensitivity in rats. Neurogastroenterol. Motil. 22, e69-e76. doi: 10.1111/j.1365-2982.2009.01395.x

Olsen, R. W., and Sieghart, W. (2008). International Union of Pharmacology. LXX. Subtypes of gamma-aminobutyric acid(A) receptors: classification on the basis of subunit composition, pharmacology, and function. Update. Pharmacol. Rev. 60, 243-260. doi: 10.1124/pr.108.00505

Ossipov, M. H., Lai, J., Malan, T. P. Jr., and Porreca, F. (2000). Spinal and supraspinal mechanisms of neuropathic pain. Ann. N. Y. Acad. Sci. 909, 12-24. doi: 10.1111/j.1749-6632.2000.tb06673.x

Ouyang, A., and Wrzos, H. F. (2006). Contribution of gender to pathophysiology and clinical presentation of IBS: should management be different in women? Am. J. Gastroenterol. 101, S602-S609. doi: 10.1111/j.1572-0241.2006.00975.x

Palazzo, E., Marabese, I., De Novellis, V., Rossi, F., and Maione, S. (2014). Supraspinal metabotropic glutamate receptors: a target for pain relief and beyond. Eur. J. Neurosci. 39, 444-454. doi: 10.1111/ejn.12398

Palecek, J. (2004). The role of dorsal columns pathway in visceral pain. Physiol. Res. 53(Suppl. 1), S125-S130.

Patel, S., Hill, M. N., Cheer, J. F., Wotjak, C. T., and Holmes, A. (2017). The endocannabinoid system as a target for novel anxiolytic drugs. Neurosci. Biobehav. Rev. 76, 56-66. doi: 10.1016/j.neubiorev.2016.12.033

Pertwee, R. G., Howlett, A. C., Abood, M. E., Alexander, S. P., Di Marzo, V., Elphick, M. R., et al. (2010). International Union of Basic and Clinical Pharmacology. LXXIX. Cannabinoid receptors and their ligands: beyond CB(1) and CB(2). Pharmacol. Rev. 62, 588-631. doi: 10.1124/pr.110.003004

Petrenko, A. B., Yamazaki, M., Sakimura, K., Kano, M., and Baba, H. (2014). Augmented tonic pain-related behavior in knockout mice lacking monoacylglycerol lipase, a major degrading enzyme for the endocannabinoid 2-arachidonoylglycerol. Behav. Brain Res. 271C, 51-58. doi: 10.1016/j.bbr.2014.05.063

Pokusaeva, K., Johnson, C., Luk, B., Uribe, G., Fu, Y., Oezguen, N., et al. (2017). GABA-producing Bifidobacterium dentium modulates visceral sensitivity in the intestine. Neurogastroenterol. Motil. 29:e12904. doi: 10.1111/nmo.12904

Prager, E. M., Brielmaier, J., Bergstrom, H. C., Mcguire, J., and Johnson, L. R. (2010). Localization of mineralocorticoid receptors at mammalian synapses. PLoS ONE 5:e14344. doi: 10.1371/journal.pone.0014344

Price, J. L. (1999). Prefrontal cortical networks related to visceral function and mood. Ann. N. Y. Acad. Sci. 877, 383-396. doi: 10.1111/j.1749-6632.1999.tb09278.x

Prusator, D. K., and Greenwood-Van Meerveld, B. (2015). Gender specific effects of neonatal limited nesting on viscerosomatic sensitivity and anxiety-like behavior in adult rats. Neurogastroenterol. Motil. 27, 72-81. doi: 10.1111/nmo.12472

Prusator, D. K., and Greenwood-Van Meerveld, B. (2016a). Sex differences in stress-induced visceral hypersensitivity following early life adversity: a two hit model. Neurogastroenterol. Motil. 28, 1876-1889. doi: 10.1111/nmo.12891

Prusator, D. K., and Greenwood-Van Meerveld, B. (2016b). Sex-related differences in pain behaviors following three early life stress paradigms. Biol. Sex Differ. 7, 29. doi: 10.1186/s13293-016-0082-x

Prusator, D. K., and Greenwood-Van Meerveld, B. (2017). Amygdala-mediated mechanisms regulate visceral hypersensitivity in adult females following early life stress: importance of the glucocorticoid receptor and corticotropinreleasing factor. Pain 158, 296-305. doi: 10.1097/j.pain.0000000000000759

Qi, Q. Q., Chen, F. X., Zhao, D. Y., Li, L. X., Wang, P., Li, Y. Q., et al. (2016). Colonic mucosal N-methyl-D-aspartate receptor mediated visceral hypersensitivity in a mouse model of irritable bowel syndrome. J. Dig. Dis. 17, 448-457. doi: 10.1111/1751-2980.12374

Qi, Q., Chen, F., Zhang, W., Wang, P., Li, Y., and Zuo, X. (2017). Colonic Nmethyl-d-aspartate receptor contributes to visceral hypersensitivity in irritable bowel syndrome. J. Gastroenterol. Hepatol. 32, 828-836. doi: 10.1111/jgh.13588

Qi, R., Liu, C., Ke, J., Xu, Q., Ye, Y., Jia, L., et al. (2016). Abnormal amygdala resting-state functional connectivity in irritable bowel syndrome. AJNR Am. J. Neuroradiol. 37, 1139-1145. doi: 10.3174/ajnr.A4655

Racine, M., Tousignant-Laflamme, Y., Kloda, L. A., Dion, D., Dupuis, G., and Choiniere, M. (2012). A systematic literature review of 10 years of research on sex/gender and pain perception - part 2: do biopsychosocial factors alter pain sensitivity differently in women and men? Pain 153, 619-635. doi: 10.1016/j.pain.2011.11.026 
Radley, J. J., Anderson, R. M., Hamilton, B. A., Alcock, J. A., and RomigMartin, S. A. (2013). Chronic stress-induced alterations of dendritic spine subtypes predict functional decrements in an hypothalamo-pituitaryadrenal-inhibitory prefrontal circuit. J. Neurosci. 33, 14379-14391. doi: 10.1523/JNEUROSCI.0287-13.2013

Reichling, D. B., and Levine, J. D. (2009). Critical role of nociceptor plasticity in chronic pain. Trends Neurosci. 32, 611-618. doi: 10.1016/j.tins.2009.07.007

Reichling, D. B., Green, P. G., and Levine, J. D. (2013). The fundamental unit of pain is the cell. Pain 154(Suppl. 1), S2-S9. doi: 10.1016/j.pain.2013.05.037

Reul, J. M., and de Kloet, E. R. (1985). Two receptor systems for corticosterone in rat brain: microdistribution and differential occupation. Endocrinology 117, 2505-2511. doi: 10.1210/endo-117-6-2505

Reyes, B. A., Carvalho, A. F., Vakharia, K., and Van Bockstaele, E. J. (2011). Amygdalar peptidergic circuits regulating noradrenergic locus coeruleus neurons: linking limbic and arousal centers. Exp. Neurol. 230, 96-105. doi: 10.1016/j.expneurol.2011.04.001

Rice, C. J., Sandman, C. A., Lenjavi, M. R., and Baram, T. Z. (2008). A novel mouse model for acute and long-lasting consequences of early life stress. Endocrinology 149, 4892-4900. doi: 10.1210/en.2008-0633

Rosztóczy, A., Fioramonti, J., Jarmay, K., Barreau, F., Wittmann, T., and Bueno, L. (2003). Influence of sex and experimental protocol on the effect of maternal deprivation on rectal sensitivity to distension in the adult rat. Neurogastroenterol. Motil. 15, 679-686. doi: 10.1046/j.1350-1925.2003.00451.x

Saab, C. Y. (2012). Pain-related changes in the brain: diagnostic and therapeutic potentials. Trends Neurosci. 35, 629-637. doi: 10.1016/j.tins.2012.06.002

Sagami, Y., Shimada, Y., Tayama, J., Nomura, T., Satake, M., Endo, Y., et al. (2004). Effect of a corticotropin releasing hormone receptor antagonist on colonic sensory and motor function in patients with irritable bowel syndrome. Gut 53, 958-964. doi: 10.1136/gut.2003.018911

Sakin, Y. S., Dogrul, A., Ilkaya, F., Seyrek, M., Ulas, U. H., Gulsen, M., et al. (2015). The effect of FAAH, MAGL, and Dual FAAH/MAGL inhibition on inflammatory and colorectal distension-induced visceral pain models in Rodents. Neurogastroenterol. Motil. 27, 936-944. doi: 10.1111/nmo.12563

Sapolsky, R. M., Mcewen, B. S., and Rainbow, T. C. (1983). Quantitative autoradiography of $\left[{ }^{3} \mathrm{H}\right]$ corticosterone receptors in rat brain. Brain Res. 271, 331-334. doi: 10.1016/0006-8993(83)90295-0

Sapsed-Byrne, S., Ma, D., Ridout, D., and Holdcroft, A. (1996). Estrous cycle phase variations in visceromotor and cardiovascular responses to colonic distension in the anesthetized rat. Brain Res. 742, 10-16. doi: 10.1016/S0006-8993(96)00989-4

Scarinci, I. C., Mcdonald-Haile, J., Bradley, L. A., and Richter, J. E. (1994). Altered pain perception and psychosocial features among women with gastrointestinal disorders and history of abuse: a preliminary model. Am. J. Med. 97, 108-118. doi: 10.1016/0002-9343(94)90020-5

Schaible, H. G., Ebersberger, A., and Natura, G. (2011). Update on peripheral mechanisms of pain: beyond prostaglandins and cytokines. Arthritis Res. Ther. 13:210. doi: 10.1186/ar3305

Schilling, O. K., and Diehl, M. (2015). Psychological vulnerability to daily stressors in old age: results of short-term longitudinal studies. Z. Gerontol. Geriatr. 48, 517-523. doi: 10.1007/s00391-015-0935-7

Schulkin, J., Gold, P. W., and Mcewen, B. S. (1998). Induction of corticotropinreleasing hormone gene expression by glucocorticoids: implication for understanding the states of fear and anxiety and allostatic load. Psychoneuroendocrinology 23, 219-243. doi: 10.1016/S0306-4530(97)00099-1

Schwartz, E. S., and Gebhart, G. F. (2014). "Visceral Pain," in Behavioral Neurobiology of Chronic Pain, eds. B.K. Taylor and D.P. Finn (New York, NY: Springer), 171-197.

Schwetz, I., Bradesi, S., Mcroberts, J. A., Sablad, M., Miller, J. C., Zhou, H., et al. (2004). Delayed stress-induced colonic hypersensitivity in male Wistar rats: role of neurokinin-1 and corticotropin-releasing factor-1 receptors. Am. J. Physiol. Gastrointest. Liver Physiol. 286, G683-G691. doi: 10.1152/ajpgi.00358.2003

Sengupta, J. N., Pochiraju, S., Kannampalli, P., Bruckert, M., Addya, S., Yadav, P., et al. (2013). MicroRNA-mediated GABA Aalpha-1 receptor subunit downregulation in adult spinal cord following neonatal cystitis-induced chronic visceral pain in rats. Pain 154, 59-70. doi: 10.1016/j.pain.2012.09.002

Sevelinges, Y., Mouly, A. M., Raineki, C., Moriceau, S., Forest, C., and Sullivan, R. M. (2011). Adult depression-like behavior, amygdala and olfactory cortex functions are restored by odor previously paired with shock during infant's sensitive period attachment learning. Dev. Cogn. Neurosci. 1, 77-87. doi: 10.1016/j.dcn.2010.07.005

Shen, L., Yang, X. J., Qian, W., and Hou, X. H. (2010). The role of peripheral cannabinoid receptors type 1 in rats with visceral hypersensitivity induced by chronic restraint stress. J. Neurogastroenterol. Motil. 16, 281-290. doi: 10.5056/jnm.2010.16.3.281

Shepard, J. D., Barron, K. W., and Myers, D. A. (2000). Corticosterone delivery to the amygdala increases corticotropin-releasing factor mRNA in the central amygdaloid nucleus and anxiety-like behavior. Brain Res. 861, 288-295. doi: 10.1016/S0006-8993(00)02019-9

Silos-Santiago, I., Hannig, G., Eutamene, H., Ustinova, E. E., Bernier, S. G., Ge, P., et al. (2013). Gastrointestinal pain: unraveling a novel endogenous pathway through uroguanylin/guanylate cyclase-C/cGMP activation. Pain 154, 1820-1830. doi: 10.1016/j.pain.2013.05.044

Stanisor, O. I., Van Diest, S. A., Yu, Z., Welting, O., Bekkali, N., Shi, J., et al. (2013). Stress-induced visceral hypersensitivity in maternally separated rats can be reversed by peripherally restricted histamine-1-receptor antagonists. PLoS ONE 8:e66884. doi: 10.1371/journal.pone.0066884

Staud, R. (2012). Abnormal endogenous pain modulation is a shared characteristic of many chronic pain conditions. Expert Rev. Neurother. 12, 577-585. doi: $10.1586 /$ ern. 12.41

Stemkowski, P. L., and Smith, P. A. (2012). Sensory neurons, ion channels, inflammation and the onset of neuropathic pain. Can. J. Neurol. Sci. 39, 416-435. doi: 10.1017/S0317167100013937

Su, J., Tanaka, Y., Muratsubaki, T., Kano, M., Kanazawa, M., and Fukudo, S. (2015). Injection of corticotropin-releasing hormone into the amygdala aggravates visceral nociception and induces noradrenaline release in rats. Neurogastroenterol. Motil. 27, 30-39. doi: 10.1111/nmo.12462

Sullivan, R. M., Landers, M., Yeaman, B., and Wilson, D. A. (2000). Good memories of bad events in infancy. Nature 407, 38-39. doi: 10.1038/35024156

Sun, H., Xu, S., Yi, L., Chen, Y., Wu, P., Cao, Z., et al. (2016). Role of 5-HT1A receptor in insular cortex mediating stress - induced visceral sensory dysfunction. Neurogastroenterol. Motil. 28, 1104-1113. doi: $10.1111 /$ nmo. 12815

Taguchi, R., Shikata, K., Furuya, Y., Hirakawa, T., Ino, M., Shin, K., et al. (2017). Selective corticotropin-releasing factor 1 receptor antagonist E2508 reduces restraint stress-induced defecation and visceral pain in rat models. Psychoneuroendocrinology 75, 110-115. doi: 10.1016/j.psyneuen.2016.10.025

Takasaki, I., Kurihara, T., Saegusa, H., Zong, S., and Tanabe, T. (2005). Effects of glucocorticoid receptor antagonists on allodynia and hyperalgesia in mouse model of neuropathic pain. Eur. J. Pharmacol. 524, 80-83. doi: 10.1016/j.ejphar.2005.09.045

Talley, N. J., Fett, S. L., Zinsmeister, A. R., and Melton, L. J. III. (1994). Gastrointestinal tract symptoms and self-reported abuse: a population-based study. Gastroenterology 107, 1040-1049. doi: 10.1016/0016-5085(94)90228-3

Tanaka, Y., Kanazawa, M., Kano, M., Morishita, J., Hamaguchi, T., Van Oudenhove, L., et al. (2016). Differential activation in amygdala and plasma noradrenaline during colorectal distention by administration of corticotropin-releasing hormone between healthy individuals and patients with irritable bowel syndrome. PLOS ONE 11:e0157347. doi: 10.1371/journal.pone. 0157347

Tang, B., Ji, Y., and Traub, R. J. (2008). Estrogen alters spinal NMDA receptor activity via a PKA signaling pathway in a visceral pain model in the rat. Pain 137, 540-549. doi: 10.1016/j.pain.2007.10.017

Tang, D., Qian, A. H., Song, D. D., Ben, Q. W., Yao, W. Y., Sun, J., et al. (2015). Role of the potassium chloride cotransporter isoform 2-mediated spinal chloride homeostasis in a rat model of visceral hypersensitivity. Am. J. Physiol. Gastrointest. Liver Physiol. 308, G767-G778. doi: 10.1152/ajpgi. 00313.2014

Tang, H. L., Zhang, G., Ji, N. N., Du, L., Chen, B. B., Hua, R., et al. (2017). Toll-like receptor 4 in paraventricular nucleus mediates visceral hypersensitivity induced by maternal separation. Front. Pharmacol. 8:309. doi: 10.3389/fphar.2017.00309

Tao, Y. X. (2012). AMPA receptor trafficking in inflammation-induced dorsal horn central sensitization. Neurosci. Bull. 28, 111-120. doi: $10.1007 / \mathrm{s} 12264-012-1204-\mathrm{z}$

Timmermans, W., Xiong, H., Hoogenraad, C. C., and Krugers, H. J. (2013). Stress and excitatory synapses: from health to disease. Neuroscience 248, 626-636. doi: 10.1016/j.neuroscience.2013.05.043 
Tramullas, M., Finger, B. C., Moloney, R. D., Golubeva, A. V., Moloney, G., Dinan, T. G., et al. (2014). Toll-like receptor 4 regulates chronic stress-induced visceral pain in mice. Biol. Psychiatry 76, 340-348. doi: 10.1016/j.biopsych.2013.11.004

Tran, L., and Greenwood-Van Meerveld, B. (2012). Altered expression of glucocorticoid receptor and corticotropin-releasing factor in the central amygdala in response to elevated corticosterone. Behav. Brain Res. 234, 380-385. doi: 10.1016/j.bbr.2012.07.010

Tran, L., Chaloner, A., Sawalha, A. H., and Greenwood Van-Meerveld, B. (2013). Importance of epigenetic mechanisms in visceral pain induced by chronic water avoidance stress. Psychoneuroendocrinology 38, 898-906. doi: 10.1016/j.psyneuen.2012.09.016

Tran, L., Schulkin, J., and Greenwood-Van Meerveld, B. (2014). Importance of CRF receptor-mediated mechanisms of the bed nucleus of the stria terminalis in the processing of anxiety and pain. Neuropsychopharmacology 39, 2633-2645. doi: $10.1038 /$ npp.2014.117

Tran, L., Schulkin, J., Ligon, C. O., and Greenwood-Van Meerveld, B. (2015). Epigenetic modulation of chronic anxiety and pain by histone deacetylation. Mol. Psychiatry 20, 1219-1231. doi: 10.1038/mp.2014.122

Tran, L., Wiskur, B., and Greenwood-Van Meerveld, B. (2012). The role of the anteriolateral bed nucleus of the stria terminalis in stress-induced nociception. Am. J. Physiol. Gastrointest. Liver Physiol. 302, G1301-G1309. doi: 10.1152/ajpgi.00501.2011

Tyler, K., Moriceau, S., Sullivan, R. M., and Greenwood-Van Meerveld, B. (2007). Long-term colonic hypersensitivity in adult rats induced by neonatal unpredictable vs predictable shock. Neurogastroenterol. Motil. 19, 761-768. doi: 10.1111/j.1365-2982.2007.00955.x

Uht, R. M., Anderson, C. M., Webb, P., and Kushner, P. J. (1997). Transcriptional activities of estrogen and glucocorticoid receptors are functionally integrated at the AP-1 response element. Endocrinology 138, 2900-2908. doi: 10.1210/endo.138.7.5244

Vamvakopoulos, N. C., and Chrousos, G. P. (1993). Evidence of direct estrogenic regulation of human corticotropin-releasing hormone gene expression. Potential implications for the sexual dimophism of the stress response and immune/inflammatory reaction. J. Clin. Invest. 92, 1896-1902. doi: $10.1172 / J C I 116782$

van den Wijngaard, R. M., Klooker, T. K., Welting, O., Stanisor, O. I., Wouters, M. M., Van Der Coelen, D., et al. (2009). Essential role for TRPV1 in stress-induced (mast cell-dependent) colonic hypersensitivity in maternally separated rats. Neurogastroenterol. Motil. 21, 1107-e1194. doi: 10.1111/j.1365-2982.2009.01339.x

van den Wijngaard, R. M., Stanisor, O. I., Van Diest, S. A., Welting, O., Wouters, M. M., Cailotto, C., et al. (2013). Susceptibility to stress induced visceral hypersensitivity in maternally separated rats is transferred across generations. Neurogastroenterol. Motil. 25, e780-e790. doi: 10.1111/nmo.12202

van den Wijngaard, R. M., Stanisor, O. I., Van Diest, S. A., Welting, O., Wouters, M. M., De Jonge, W. J., et al. (2012). Peripheral alpha-helical CRF (9-41) does not reverse stress-induced mast cell dependent visceral hypersensitivity in maternally separated rats. Neurogastroenterol. Motil. 24, 274-282, e111. doi: $10.1111 / j .1365-2982.2011 .01840 . x$

Vanner, S., Greenwood-Van Meerveld, B., Mawe, G., Shea-Donohue, T., Verdu, E. F., Wood, J., et al. (2016). Fundamentals of neurogastroenterology: basic science. Gastroenterology 150, 1280-1291. doi: 10.1053/j.gastro.2016.02.018

Vendruscolo, L. F., Pamplona, F. A., and Takahashi, R. N. (2004). Strain and sex differences in the expression of nociceptive behavior and stress-induced analgesia in rats. Brain Res. 1030, 277-283. doi: 10.1016/j.brainres.2004. 10.016

Verne, G. N., Price, D. D., Callam, C. S., Zhang, B., Peck, J., and Zhou, Q. (2012). Viscerosomatic facilitation in a subset of IBS patients, an effect mediated by N-methyl-D-aspartate receptors. J. Pain 13, 901-909. doi: 10.1016/j.jpain.2012.06.002

Voß, U., Lewerenz, A., and Nieber, K. (2013). "Treatment of irritable bowel syndrome: sex and gender specific aspects," in Sex and Gender Differences in Pharmacology. Handbook of Experimental Pharmacology, Vol. 214, ed V. Regitz-Zagrosek (Berlin: Springer), 473-497. doi: 10.1007/978-3-642-30726-3_21

Vyas, A., Mitra, R., Shankaranarayana Rao, B. S., and Chattarji, S. (2002). Chronic stress induces contrasting patterns of dendritic remodeling in hippocampal and amygdaloid neurons. J. Neurosci. 22, 6810-6818.
Waddington, C. H. (1942). Canalization of development and the inheritance of acquired characters. Nature 150, 563-565. doi: 10.1038/150563a0

Wang, J., Zhang, X., Cao, B., Liu, J., and Li, Y. (2015). Facilitation of synaptic transmission in the anterior cingulate cortex in viscerally hypersensitive rats. Cereb. Cortex 25, 859-868. doi: 10.1093/cercor/bht273

Wang, S., Lim, G., Zeng, Q., Sung, B., Ai, Y., Guo, G., et al. (2004). Expression of central glucocorticoid receptors after peripheral nerve injury contributes to neuropathic pain behaviors in rats. J. Neurosci. 24, 8595-8605. doi: 10.1523/JNEUROSCI.3058-04.2004

Wang, W., Xin, H., Fang, X., Dou, H., Liu, F., Huang, D., et al. (2017). Isomalto-oligosaccharides ameliorate visceral hyperalgesia with repair damage of ileal epithelial ultrastructure in rats. PLOS ONE 12:e0175276. doi: 10.1371/journal.pone.0175276

Wang, Y., Qu, R., Hu, S., Xiao, Y., Jiang, X., and Xu, G. Y. (2012). Upregulation of cystathionine beta-synthetase expression contributes to visceral hyperalgesia induced by heterotypic intermittent stress in rats. PLOS ONE 7:e53165. doi: 10.1371/journal.pone.0053165

Wang, Z., Chang, H. H., Gao, Y., Zhang, R., Guo, Y., Holschneider, D. P., et al. (2017). Effects of water avoidance stress on peripheral and central responses during bladder filling in the rat: a multidisciplinary approach to the study of urologic chronic pelvic pain syndrome (MAPP) research network study. PLoS ONE 12:e0182976. doi: 10.1371/journal.pone.01 82976

Watson, R. P., Lilley, E., Panesar, M., Bhalay, G., Langridge, S., Tian, S. S., et al. (2012). Increased prokineticin 2 expression in gut inflammation: role in visceral pain and intestinal ion transport. Neurogastroenterol. Motil. 24,65-e12. doi: 10.1111/j.1365-2982.2011.01804.x

Weaver, K. R., Sherwin, L. B., Walitt, B., Melkus, G. D., and Henderson, W. A. (2016). Neuroimaging the brain-gut axis in patients with irritable bowel syndrome. World J. Gastrointest. Pharmacol. Ther. 7, 320-333. doi: 10.4292/wjgpt.v7.i2.320

Weng, Y., Qi, R., Liu, C., Ke, J., Xu, Q., Wang, F., et al. (2016). Disrupted functional connectivity density in irritable bowel syndrome patients. Brain Imaging Behav. doi: 10.1007/s11682-016-9653-z. [Epub ahead of print].

Whitehead, W. E., Cheskin, L. J., Heller, B. R., Robinson, J. C., Crowell, M. D., Benjamin, C., et al. (1990). Evidence for exacerbation of irritable bowel syndrome during menses. Gastroenterology 98, 1485-1489. doi: 10.1016/0016-5085(90)91079-L

Widgerow, A. D., and Kalaria, S. (2012). Pain mediators and wound healing-establishing the connection. Burns 38, 951-959. doi: 10.1016/j.burns.2012.05.024

Wilder-Smith, C. H. (2011). The balancing act: endogenous modulation of pain in functional gastrointestinal disorders. Gut 60, 1589-1599. doi: 10.1136/gutjnl-2011-300253

Wilder-Smith, C. H., Schindler, D., Lovblad, K., Redmond, S. M., and Nirkko, A. (2004). Brain functional magnetic resonance imaging of rectal pain and activation of endogenous inhibitory mechanisms in irritable bowel syndrome patient subgroups and healthy controls. Gut 53, 1595-1601. doi: 10.1136/gut.2003.028514

Winchester, W. J., Johnson, A., Hicks, G. A., Gebhart, G. F., Greenwood-Van Meerveld, B., and Mclean, P. G. (2009). Inhibition of endothelial cell adhesion molecule expression improves colonic hyperalgaesia. Neurogastroenterol. Motil. 21, 189-196. doi: 10.1111/j.1365-2982.2008.01222.x

Winston, J. H., Li, Q., and Sarna, S. K. (2014). Chronic prenatal stress epigenetically modifies spinal cord BDNF expression to induce sex-specific visceral hypersensitivity in offspring. Neurogastroenterol. Motil. 26, 715-730. doi: 10.1111/nmo.12326

Winston, J. H., Xu, G. Y., and Sarna, S. K. (2010). Adrenergic stimulation mediates visceral hypersensitivity to colorectal distension following heterotypic chronic stress. Gastroenterology 138, 294-304.e3. doi: 10.1053/j.gastro.2009.09.054

Woodhams, S. G., Chapman, V., Finn, D. P., Hohmann, A. G., and Neugebauer, V. (2017). The cannabinoid system and pain. Neuropharmacology 124, 105-120. doi: 10.1016/j.neuropharm.2017.06.015

Woolf, C. J., and Salter, M. W. (2000). Neuronal plasticity: increasing the gain in pain. Science 288, 1765-1769. doi: 10.1126/science.288.5472.1765

Woolley, C. S., Gould, E., and Mcewen, B. S. (1990). Exposure to excess glucocorticoids alters dendritic morphology of adult hippocampal pyramidal neurons. Brain Res. 531, 225-231. doi: 10.1016/0006-8993(90)90778-A 
Xu, D., Gao, J., Gillilland, M. III., Wu, X., Song, I., Kao, J. Y., et al. (2014). Rifaximin alters intestinal bacteria and prevents stress-induced gut inflammation and visceral hyperalgesia in rats. Gastroenterology 146, 484-496.e4. doi: 10.1053/j.gastro.2013.10.026

Yang, C. Q., Duan, L. P., Qiao, P. T., Zhao, L., and Guo, L. L. (2015). Increased VGLUT3 involved in visceral hyperalgesia in a rat model of irritable bowel syndrome. World J. Gastroenterol. 21, 2959-2966. doi: 10.3748/wjg.v21.i10.2959

Yarushkina, N. I., Bagaeva, T. R., and Filaretova, L. P. (2009). Analgesic actions of corticotropin-releasing factor (CRF) on somatic pain sensitivity: involvement of glucocorticoid and CRF-2 receptors. Neurosci. Behav. Physiol. 39, 819-823. doi: 10.1007/s11055-009-9212-9

Yi, L., Sun, H., Ge, C., Chen, Y., Peng, H., Jiang, Y., et al. (2014). Role of insular cortex in visceral hypersensitivity model in rats subjected to chronic stress. Psychiatry Res. 220, 1138-1143. doi: 10.1016/j.psychres.2014.09.019

Zeilhofer, H. U., Wildner, H., and Yevenes, G. E. (2012). Fast synaptic inhibition in spinal sensory processing and pain control. Physiol. Rev. 92, 193-235. doi: 10.1152 /physrev.00043.2010

Zhang, C., Rui, Y. Y., Zhou, Y. Y., Ju, Z., Zhang, H. H., Hu, C. Y., et al. (2014). Adrenergic beta2-receptors mediates visceral hypersensitivity induced by heterotypic intermittent stress in rats. PLOS ONE 9:e94726. doi: 10.1371/journal.pone.0094726

Zhang, G., Yu, L., Chen, Z. Y., Zhu, J. S., Hua, R., Qin, X., et al. (2016a). Activation of corticotropin-releasing factor neurons and microglia in paraventricular nucleus precipitates visceral hypersensitivity induced by colorectal distension in rats. Brain Behav. Immun. 55, 93-104. doi: 10.1016/j.bbi.2015.12.022

Zhang, G., Zhao, B. X., Hua, R., Kang, J., Shao, B. M., Carbonaro, T. M., et al. (2016b). Hippocampal microglial activation and glucocorticoid receptor down-regulation precipitate visceral hypersensitivity induced by colorectal distension in rats. Neuropharmacology 102, 295-303. doi: 10.1016/j.neuropharm.2015.11.028

Zhang, J., and Banerjee, B. (2015). Role of MicroRNA in visceral pain. J. Neurogastroenterol. Motil. 21, 159-171. doi: 10.5056/jnm15027

Zhang, J., Yu, J., Kannampalli, P., Nie, L., Meng, H., Medda, B., et al. (2017). miRNA-mediated downregulation of KCC2 and VGAT expression in spinal cord contributes to neonatal cystitis-induced visceral pain in rats. Pain 158, 2461-2474. doi: 10.1097/j.pain.0000000000001057

Zhao, J., Wang, J., Dong, L., Shi, H., Wang, Z., Ding, H., et al. (2011). A protease inhibitor against acute stress-induced visceral hypersensitivity and paracellular permeability in rats. Eur. J. Pharmacol. 654, 289-294. doi: 10.1016/j.ejphar.2010.12.032

Zheng, G., Hong, S., Hayes, J. M., and Wiley, J. W. (2015). Chronic stress and peripheral pain: evidence for distinct, region-specific changes in visceral and somatosensory pain regulatory pathways. Exp. Neurol. 273, 301-311. doi: 10.1016/j.expneurol.2015.09.013
Zhou, L., Huang, J., Gao, J., Zhang, G., and Jiang, J. (2014). NMDA and AMPA receptors in the anterior cingulate cortex mediates visceral pain in visceral hypersensitivity rats. Cell. Immunol. 287, 86-90. doi: 10.1016/j.cellimm.2013.12.001

Zhou, Q., and Verne, G. N. (2011). New insights into visceral hypersensitivityclinical implications in IBS. Nat. Rev. Gastroenterol. Hepatol. 8, 349-355. doi: $10.1038 /$ nrgastro.2011.83

Zhou, Q., Costinean, S., Croce, C. M., Brasier, A. R., Merwat, S., Larson, S. A., et al. (2015). MicroRNA 29 targets nuclear factor-kappaB-repressing factor and Claudin 1 to increase intestinal permeability. Gastroenterology 148, 158-169.e8. doi: 10.1053/j.gastro.2014.09.037

Zhou, Q., Price, D. D., Callam, C. S., Woodruff, M. A., and Verne, G. N. (2011). Effects of the N-methyl-D-aspartate receptor on temporal summation of second pain (wind-up) in irritable bowel syndrome. J. Pain 12, 297-303. doi: 10.1016/j.jpain.2010.09.002

Zhou, Q., Souba, W. W., Croce, C. M., and Verne, G. N. (2010). MicroRNA29a regulates intestinal membrane permeability in patients with irritable bowel syndrome. Gut 59, 775-784. doi: 10.1136/gut.2009.181834

Zhou, Q., Yang, L., Larson, S., Basra, S., Merwat, S., Tan, A., et al. (2016). Decreased miR-199 augments visceral pain in patients with IBS through translational upregulation of TRPV1. Gut 65, 797-805. doi: 10.1136/gutjnl-2013306464

Zhou, X. P., Sha, J., Huang, L., Li, T. N., Zhang, R. R., Tang, M. D., et al. (2016). Nesfatin-1/NUCB2 in the amygdala influences visceral sensitivity via glucocorticoid and mineralocorticoid receptors in male maternal separation rats. Neurogastroenterol. Motil. 28, 1545-1553. doi: 10.1111/nmo. 12853

Zhou, Y. Y., Wanner, N. J., Xiao, Y., Shi, X. Z., Jiang, X. H., Gu, J. G., et al. (2012). Electroacupuncture alleviates stress-induced visceral hypersensitivity through an opioid system in rats. World J. Gastroenterol. 18, 7201-7211. doi: 10.3748 /wg.v18.i48.7201

Zhuo, M. (2017). Ionotropic glutamate receptors contribute to pain transmission and chronic pain. Neuropharmacology 112, 228-234. doi: 10.1016/j.neuropharm.2016.08.014

Conflict of Interest Statement: The authors declare that the research was conducted in the absence of any commercial or financial relationships that could be construed as a potential conflict of interest.

Copyright $\odot 2017$ Greenwood-Van Meerveld and Johnson. This is an open-access article distributed under the terms of the Creative Commons Attribution License (CC $B Y)$. The use, distribution or reproduction in other forums is permitted, provided the original author(s) or licensor are credited and that the original publication in this journal is cited, in accordance with accepted academic practice. No use, distribution or reproduction is permitted which does not comply with these terms. 